\title{
Cavola experiment site: geophysical investigations and deployment of a dense seismic array on a landslide
}

\author{
Paola Bordoni $\left({ }^{1}\right)$, John Haines $\left({ }^{2}\right)$, Giuseppe Di Giulio $\left({ }^{3}\right)$, Giuliano Milana $\left({ }^{3}\right)$, Paolo Augliera $\left({ }^{9}\right)$, \\ Michele Cercato $\left({ }^{10}\right)$, Luca Martelli $\left({ }^{5}\right)$, Fabrizio Cara $\left({ }^{3}\right)$ and the Cavola Experiment Team \\ (1) Istituto Nazionale di Geofisica e Vulcanologia, Sezione CNT, Roma, Italy \\ ${ }^{(2)}$ Bullard Laboratories, Department of Earth Sciences, University of Cambridge, U.K. \\ ${ }^{(3)}$ Istituto Nazionale di Geofisica e Vulcanologia, Sezione Romal, Roma, Italy \\ ( ${ }^{4}$ Provincia di Modena, Area Ambiente e Sviluppo Sostenibile, Modena, Italy \\ ${ }^{(5)}$ Regione Emilia Romagna, Servizio Geologico Sismico e dei Suoli, Bologna, Italy \\ $\left.{ }^{(}\right)$Provincia di Reggio Emilia, Area Pianificazione e Tutela del Territorio, Reggio Emilia, Italy \\ ${ }^{(7)}$ Comune di Toano, Servizio Tecnico, Toano (RE), Italy \\ $\left(^{8}\right)$ SEIS-UK, Geology Department, University of Leicester, U.K. \\ $\left({ }^{9}\right)$ Istituto Nazionale di Geofisica e Vulcanologia, Sezione Milano, Milano, Italy \\ $\left(^{10}\right)$ Dipartimento di Idraulica Trasporti e Strade (DITS), Facoltà di Ingegneria, \\ Università degli Studi di Roma «La Sapienza», Roma, Italy
}

(11) Dipartimento di Ingegneria delle Strutture, dei Trasporti, delle Acque, del Rilevamento del Territorio

(DISTART), Università degli Studi di Bologna, Italy

The Cavola Experiment Team is: Anna Horleston $\left({ }^{8}\right)$, Marco Cattaneo $\left({ }^{1}\right)$, Giovanna Cultrera $\left({ }^{3}\right)$, Riccardo Azzara $\left({ }^{3}\right)$, Angela Chesi $\left({ }^{1}\right)$, Gianfranco Colasanti $\left({ }^{1}\right)$, Marco Colasanti $\left({ }^{1}\right)$, Luciano Giovani $\left({ }^{1}\right)$, Vincenzo Cardinale $\left({ }^{1}\right)$,

Felice Minichiello $\left({ }^{1}\right)$, Antonio Memmolo $\left({ }^{1}\right)$, Franco Pirro $\left({ }^{1}\right)$, Simone Marzorati $\left({ }^{9}\right)$, Ezio D'Alema $\left({ }^{9}\right)$, Mariano Maistrello $\left({ }^{9}\right)$, Pino Capone $\left({ }^{11}\right)$, Sergio Del Mese $\left({ }^{1}\right)$, Elisabetta D'Anastasio $\left({ }^{1}\right)$, Arianna Pesci $\left({ }^{1}\right)$, Alessandro Amato $\left({ }^{1}\right)$, Antonio Rovelli $\left({ }^{3}\right)$, Rita Nicolini $\left({ }^{4}\right)$, Federica Manenti $\left({ }^{6}\right)$, Giancarlo Tagliatini $\left({ }^{7}\right)$, Lorenzo Del Maschio $\left({ }^{4}\right)$ and Francesca Lugli $\left({ }^{4}\right)$

\begin{abstract}
Geophysical site investigations have been performed in association with deployment of a dense array of 95 3-component seismometers on the Cavola landslide in the Northern Apennines. The aim of the array is to study propagation of seismic waves in the heterogeneous medium through comparison of observation and modelling. The small-aperture array $(130 \mathrm{~m} \times 56 \mathrm{~m})$ operated continuously for three months in 2004. Cavola landslide consists of a clay body sliding over mudstone-shale basement, and has a record of historical activity, including destruction of a small village in 1960. The site investigations include down-hole logging of $P$ - and $S$-wave travel times at a new borehole drilled within the array, two seismic refraction lines with both $P$-wave profiling and surface-wave analyses, geo-electrical profiles and seismic noise measurements. From the different approaches a consistent picture of the depths and seismic velocities for the landslide has emerged. Their estimates agree with resonance frequencies of seismic noise, and also with the logged depths to basement of $25 \mathrm{~m}$ at a new borehole and of $44 \mathrm{~m}$ at a pre-existing borehole. Velocities for $S$ waves increase with depth, from $230 \mathrm{~m} / \mathrm{s}$ at the surface to $625 \mathrm{~m} / \mathrm{s}$ in basement immediately below the landslide.
\end{abstract}

Key words landslide - seismic array - borehole measurements - seismic refraction - H/V noise spectral ratios

Mailing address: Dr.ssa Paola Bordoni, Istituto Nazionale di Geofisica e Vulcanologia, Sezione CNT, Via di Vigna Murata 605, 00143 Roma, Italy; e-mail: bordoni@ingv.it

\section{Introduction}

Several towns in the Northern Apennines are located on detrital cover, such as alluvial sediments or slope debris, and because of the region's geological history, the area has an intrinsic proneness to landslides. There is a predominance of 
flysch rock types and melanges, whose frictional strength has been weakened by the high degree of tectonism. Furthermore, the high content of clay minerals and their propensity for absorbing water facilitates the formation and triggering of landslides. Coupled with this inherent instability, the region has moderate but continuous seismicity. How seismic waves are amplified by a landslide over the cracked basement covering the region is of clear scientific interest, as well as being of obvious concern to the local authorities. Local authorities (Provincia di Modena and Provincia di Reggio Emilia) proposed the landslide of Cavola as a possible test site: its geological and morphological setting, with the combination of human habitation and active landsliding, makes it representative of a common situation in the region.

From a seismological perspective, the scientific aim of experiment was to study the propagation of seismic wave through a heterogeneous medium and to compare unambiguously modelling and observations. The presence of heterogeneity required a dense station spacing to quantify variation of site response over short distances. This guided the decision of installing the 95 stations in a closely spaced configuration (dimension $130 \times 56 \mathrm{~m}$ ). The small-scale array was equipped with Guralp 3-component CMG6TD instruments available from NERC SEISUK. The stations recorded in a continuous mode for about three months, so the dataset has the potential for the study of amplification function using both noise and local earthquakes.

The first step towards studying the seismic wave propagation is the reconstruction of the landslide body, in terms of geometry and wave velocities. In this preliminary paper we focus on this goal achieved using a multidisciplinary approach based on geological, geophysical and seismic investigations.

In the following we will discuss: i) the geology of the Cavola area; ii) the deployment of a seismic array suitable for our purpose and the resulting dataset of seismic recordings; iii) the results of the geophysical surveys. In particular to obtain properties of the landslide we use geoelectrical measurements, seismic refraction and associated surface wave analyses, complemented by seismic noise measurements over the landslide and the surrounding area. Additionally, we had the benefit of an existing borehole in the array area, and a second stratigraphic borehole was added, including $P$ - and $S$-wave travel time logging.

\section{Geological background}

Northern Apennines are a fold and thrust belt which started forming during the Cretaceous age and are associated with the convergence and collision between the European and Adriatic plates and the consumption of the former ocean between them, the Ligurian Ocean.

The orogen is made up by the overlapping of several, highly tectonised rock units. They belong to distinct paleogeographic domains: i) the Tuscan-Umbria-Romagna Units, deposited on the passive continental Adria margin, ii) the Ligurian Units of oceanic domain, iii) the SubLigurian Units deposited in a transition environment between the oceanic domain and the continental passive margin, iv) the Epi-Ligurian Sequence deposited in the Ligurian accretionary basin and in piggy-back basins (fig. 1).

From a structural point of view the Epi-Ligurian Sequence overlies the Ligurian Units with a sharp angular unconformity. The Ligurian Units overlie the Sub-Ligurian Units and both lie on the Tuscan Umbria-Romagna Units and the former two are the top structural units of the Northern Apennines orogenic wedge (Sestini, 1970; Bettelli and De Nardo, 2001; Cerrina Feroni et al., 2002).

In the Cavola area, the lower part of the EpiLigurian Sequence outcrops consisting of highly fractured flysch rock types and clayey melanges. In particular (fig. 2, right), the Monte Piano Formation is a Middle-Late Eocene deep water pelagic marl which is covered by the Ranzano Formation, a muddy and sandstone turbidite of Late Eocene-Early Oligocene age (Martelli et al., 1998; Mancin et al., 2006). The Cavola landslide is derived from marly-calcareous flysch of the Monghidoro Formation (Upper Maastrichtian-Lower Paleocene) and Monte Venere Formation (Upper Campanian-Maastrichtian), both belonging to Ligurian Units, outcropping to the south of Cavola village (Plesi, 2002). 


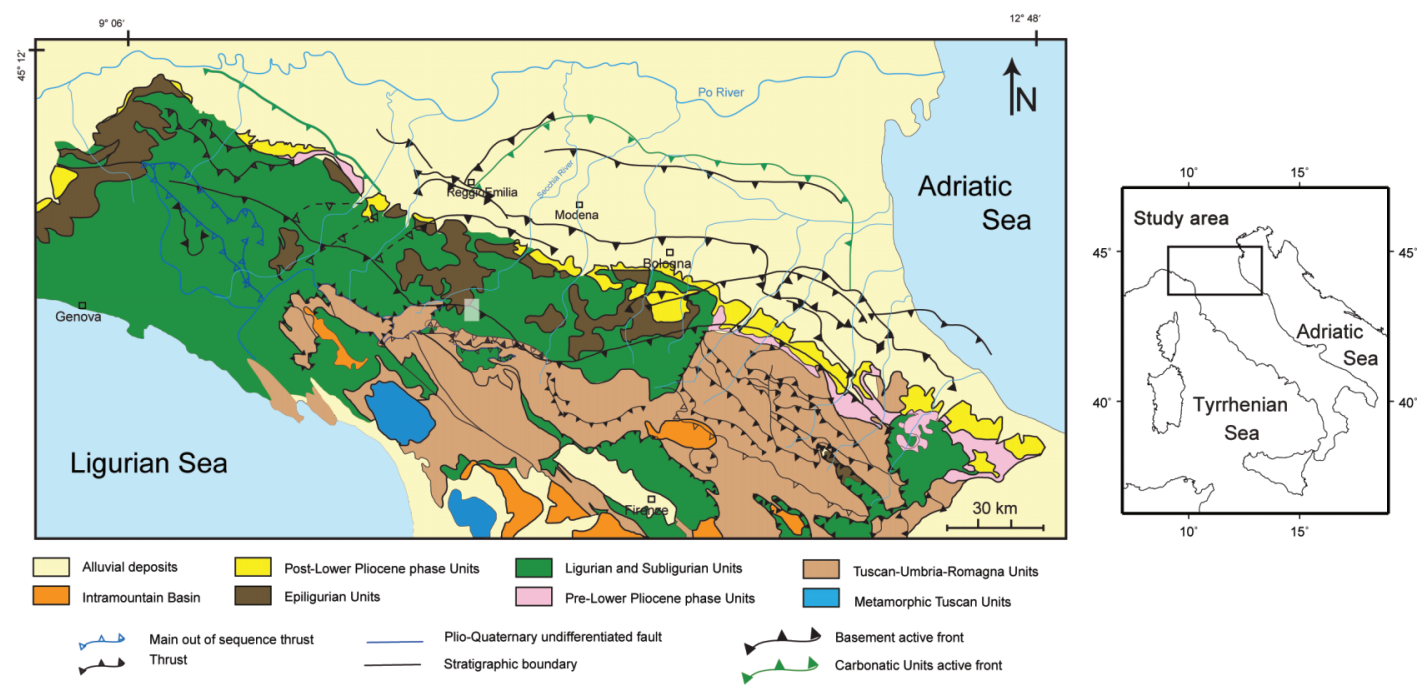

Fig. 1. Regional setting of the Emilia Apennines (redrawn from Cerrina Feroni et al., 2002). The study area is outlined with a white rectangle.
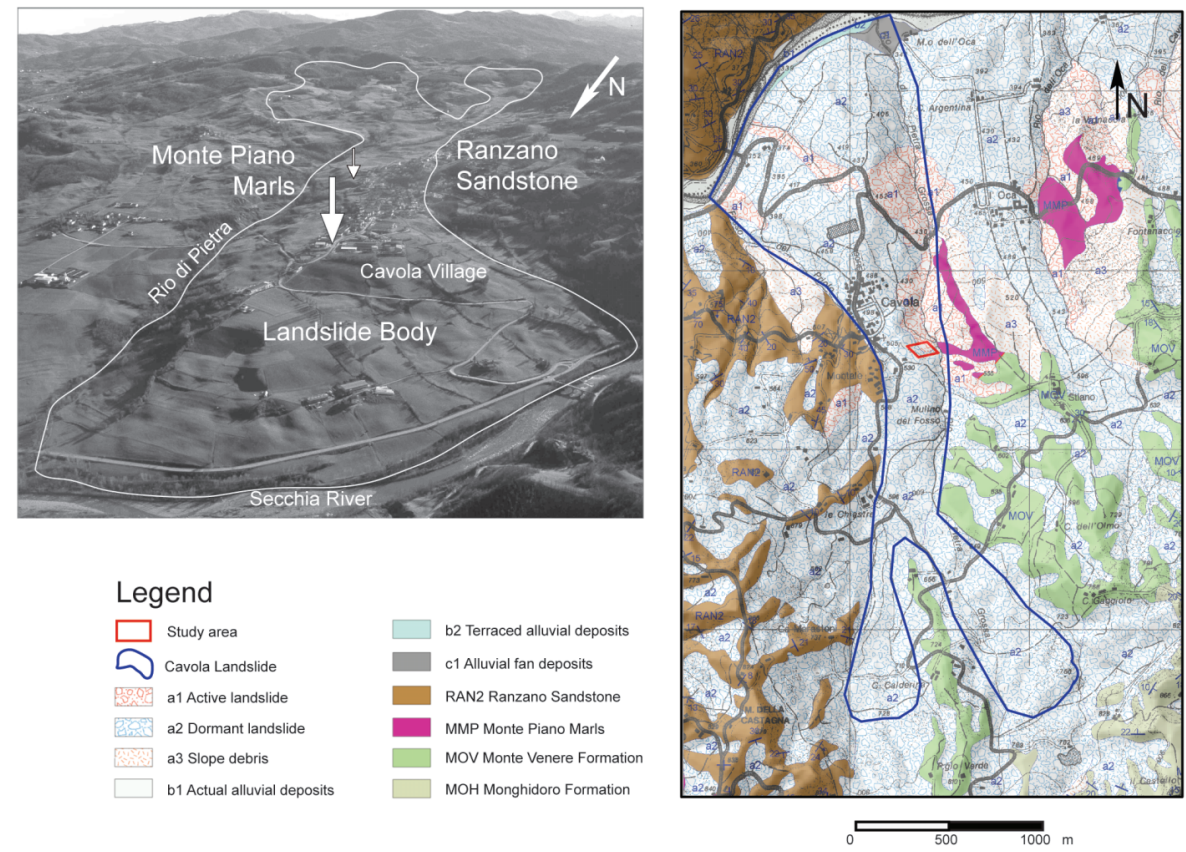

Fig. 2. Left: photograph of the Cavola landslide (courtesy of Giovanni Bertolini, unpublished). The big arrow points to the location of the borehole in Cavola village where the oldest wood fragment from the Cavola landslide was found, and our seismic array was at the other end of this arrow. The small arrow points to borehole1. Right: the Cavola site, including basement and landslide geology, redrawn from Regione Emilia Romagna (http://geo.regione.emilia-romagna.it/carg/home.htm). 


\section{Landslides}

The Ligurian and Sub-Ligurian Units and Epi-Ligurian are the rock units mainly affected by landsliding because of their geomechanical and lithological characteristics. They have been subjected to a high degree of tectonism for calcareous and sandstone rocks and have high pelite content for flysch formations. Therefore these units are very fractured and faulted and have little friction strength, while the internal flysch formations have thin layers of clay adsorbing water and triggering landslides (Bertolini and Pellegrini, 2001; CNR-RER, 1993).

Nearly all the present landslides of the Northern Apennines are ancient landslides which have been reactivated (Almagià, 1907). The oldest wood fragments found inside the Emilia Apennines landslides are radiocarbon dated as 920013500 year cal BP, which could be linked to the first activation of the earliest of these landslides. There are many more samples, coming from several landslides including Cavola, dated as 25005000 year cal BP, which for the Cavola sample (fig. 2, left) could be linked to the landslide first activation. So the bulk of these landslides bodies, making up much of the landscape, were formed by the dramatic climate changes that happened throughout the Pleistocene and Holocene (Bertolini and Pellegrini, 2001).

According to Bertolini and Pizziolo (2007) the great majority of the Emilia Apennines landslides are ancient Earth flows built by superimposition of minor events during the rainiest periods of the Pleistocene and Holocene. They are characterized by a large crown, a narrow channel and large foot and the Cavola landslide is a good example of such a morphology (fig. 2, right). In spite of their Earth flow origin, research shows that during reactivation their prevailing type of movement is sliding advancement along their basal surface, rarely by internal flow.

In particular, Cavola landslide has a length of about $4 \mathrm{~km}$ and a thickness greater than $60 \mathrm{~m}$ at the foot.

The Catalogo Frane Storiche Provincia di Reggio Emilia (Brunamonte, 1999) contains three instances of activity triggered by metereological events: in 1938 serious damage occurred to 5 houses, in 1940 there was local reactivation, while the 1960 event was the most destructive activation, involving an area of $1.3 \mathrm{~km}^{2}$ and the total destruction of a village close to Cavola the main village. Even though the activity of this landslide in the past century has been triggered by meteorological events, rather than earthquakes, it is likely that the worst case scenario would be the coincidence of a meteorological event and a large earthquake.

Recent SAR interferometric analyses coupled to inclinometers data analyses (Corsini et al., 2006) for some Emilia Apennines landslides that had been mapped as dormant over the last 10 years, show local slow movements of the landslides which accelerate during critical hydro-meteorologic periods. Cavola landslide, in particular, for the supposedly dormant period 1995-2001 has movements ranging between $10-15 \mathrm{~mm} \mathrm{yr}^{-1}$ affecting mainly areas close to the landslide side-scarps and to a new industrial district with active sliding surface at a depth of $10-15 \mathrm{~m}$.

\section{Seismicity}

Figure 3 (top) shows the instrumental seismicity from the past 20 years from CSI 1.1 catalogue (Castello et al., 2005) with magnitude $M>2.5$. Seismicity is evenly distributed along the Apennines and is mainly of crustal origin (Chiarabba et al., 2005). The upper crustal seismicity has depths in the ranges $6-8 \mathrm{~km}$ and 12 $15 \mathrm{~km}$ and describes a belt beneath the mountain chain with the largest events showing normal faulting mechanisms. The lower crust seismicity, with depths in the range $15-25 \mathrm{~km}$, is located to the east of the upper crustal belt, and the largest events show compressive and transpressive mechanisms (Frepoli and Amato, 1997; Pondrelli et al., 2002). Also, fig. 3 (top) shows historical earthquakes from the CPTI04 catalogue (Gruppo di lavoro CPTI, 2004) with intensity $I>7.0$. These are evenly distributed throughout the whole Northern Apennines area. The 1920 Garfagnana and 1835 Alpi Apuane events had intensity of $I=9.5$ (IX-X MCS). They are the biggest events located near Cavola, and were about 40 $\mathrm{km}$ southwest of the landslide. The catalogue also contains 10 other events nearby with an inten- 

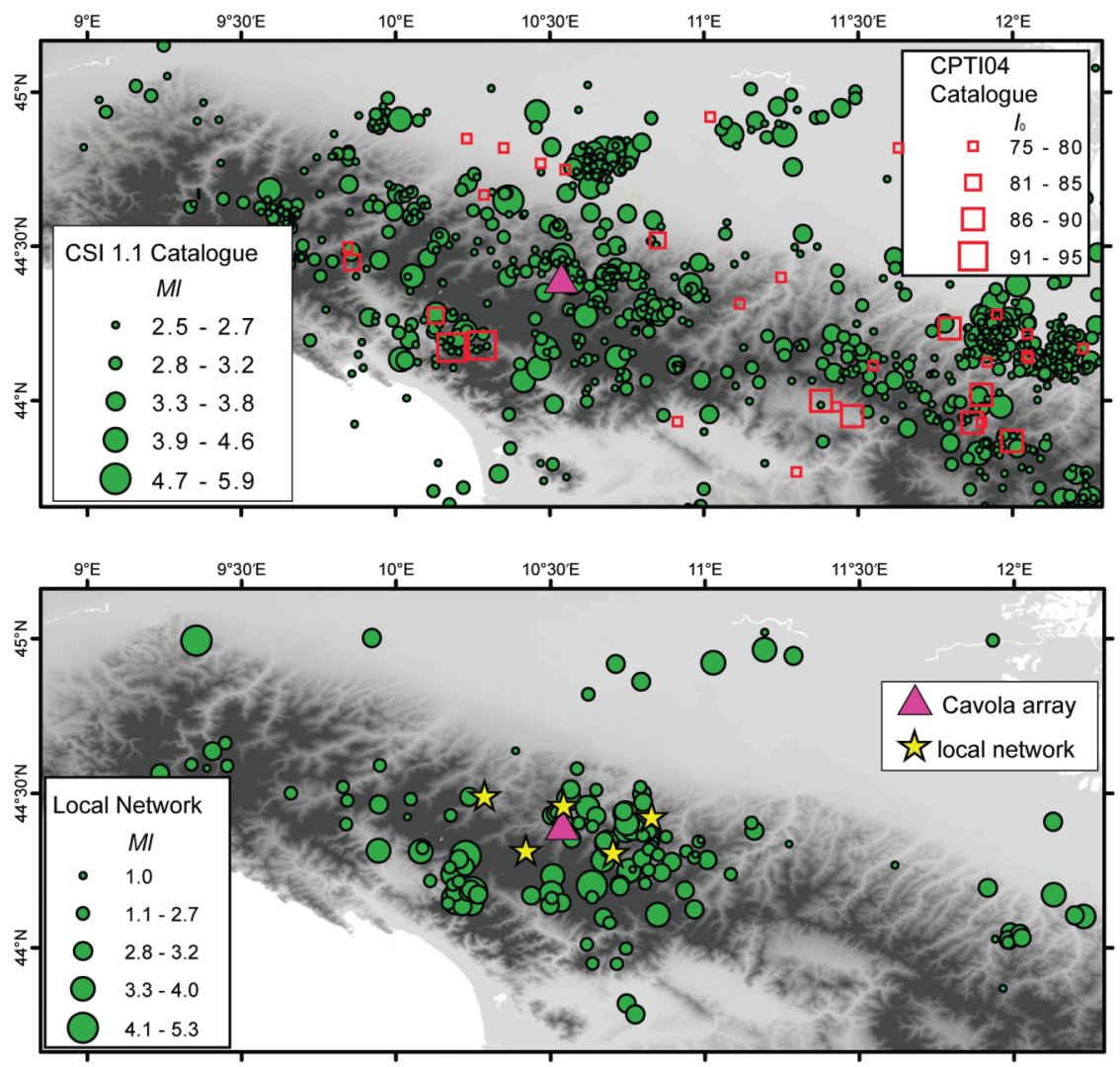

Fig. 3. Top: instrumental seismicity from CSI catalogue (1981-2002) with $M>2.5$ (Castello et al., 2005, version 1.1), historical seismicity with I>VII MCS from CPTI04 (Gruppo di Lavoro CPTI04). For the Historical seismicity the conversion from CPTI04 value to MCS is obtained by dividing by 10 , with non-integer MCS values being intermediate between the integer values on either side. Bottom: instrumental seismicity recorded by our microearthquake network during the Cavola experiment.

sity of between $I=8.5$ and $I=9$. Thus very high intensities of earthquake ground shaking are expected to occur at Cavola, and all other landslides in the Northern Apennines, on a timescale of several hundreds of years.

Figure 3 (bottom) shows the seismicity recorded by the microearthquake network and will be described later.

\section{Site selection}

The Cavola landslide (fig. 2, left) was indicated by geologists of Provincia di Modena and
Provincia di Reggio Emilia because of its geological and morphological setting, with the combination of human habitation and active landsliding being representative of a common situation in the region.

The area selected for deployment of the seismograph array is shown in fig. 4. The Cavola landslide suited our study because i) the area has been geologically mapped recently by the CARG project at a 1:10000 scale (Papani, 2002; Plesi, 2002), and, ii) independent information from a borehole (borehole1 hereafter) penetrating the bedrock was available. The stratigraphic core extracted from borehole1 shows $39 \mathrm{~m}$ of 
clay overlying the basement logged at $44 \mathrm{~m}$ depth as Monte Piano Formation. To the west of the landslide the basement is Ranzano sandstone, of turbiditic origin, and to the east of the landslide the stratigraphically deeper, deep water pelagic marl of the Monte Piano Formation is exposed, both from the Epi-Ligurian Sequence. Cavola village is on the western, supposedly dor-

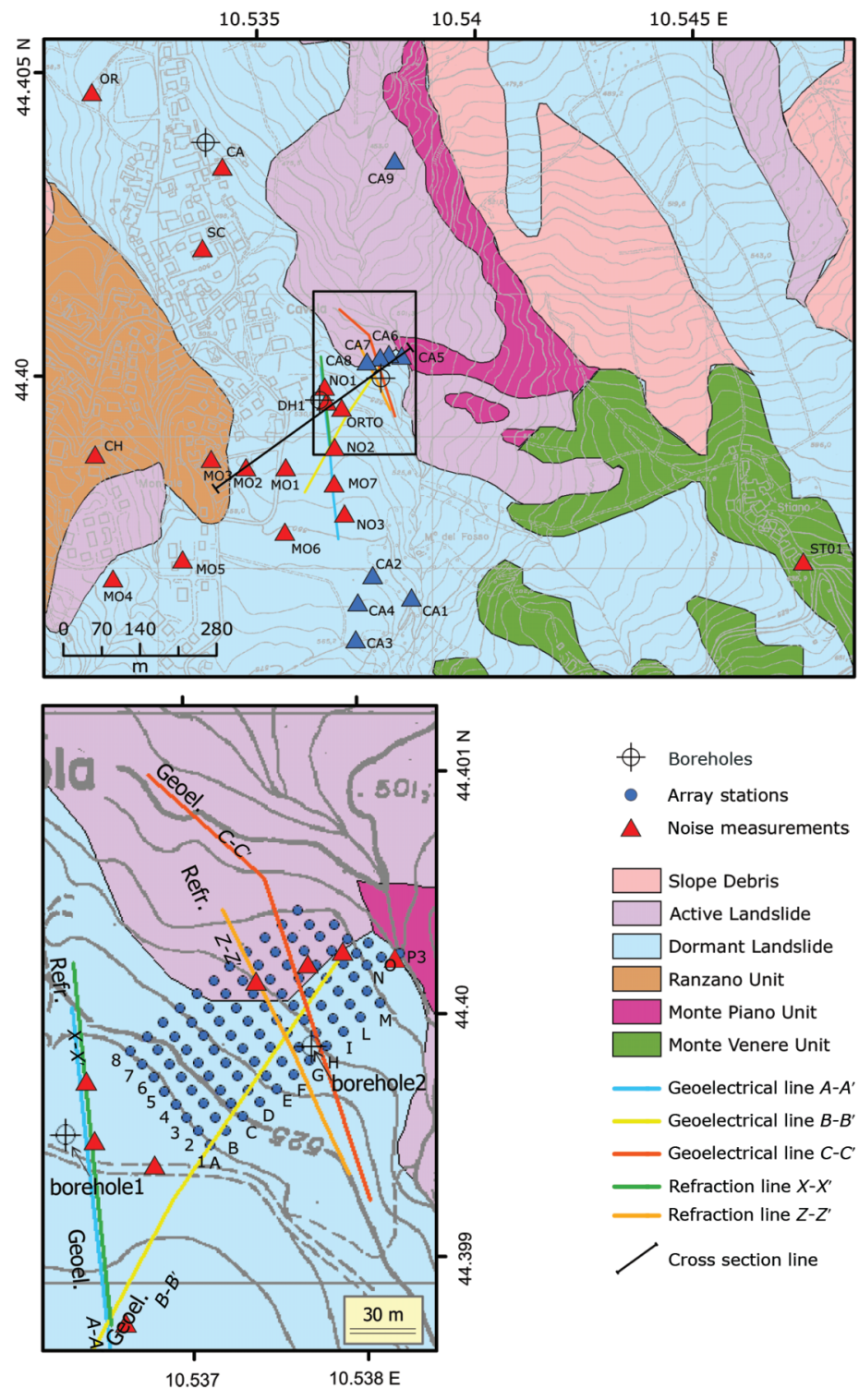

Fig. 4. The Cavola site, including basement and landslide geology, location of boreholes and geophysical measurements, layout of the seismic array and of village stations, and location of single station noise measurements. The geological map is redrawn from Regione Emilia Romagna (http://geo.regione.emilia-romagna.it/carg/home.htm). 

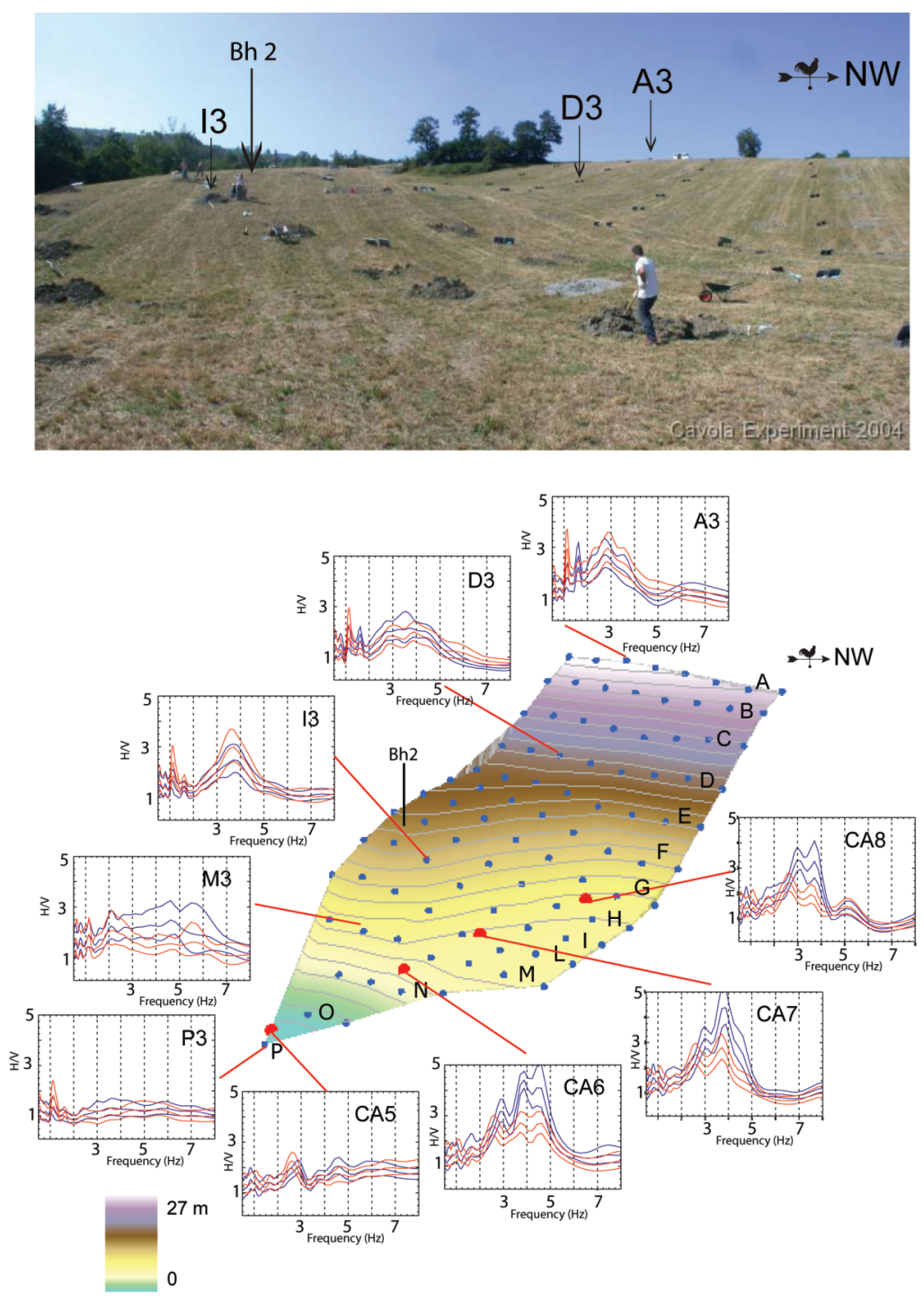

Fig. 5. Top: photograph of the array field during the deployment. Bottom: digital elevation model of the array area from data collected during the experiment using an electronic geodimeter and $H / V$ plots for stations within the array area.

mant side of the landslide, though some buildings in the village are structurally damaged, and our main array on the eastern side of the landslide crossed the mapped boundary between dormant and active landslide (fig. 4). The bottom seismometer (P3) in the array was in a stream bed and effectively on the Monte Piano bedrock at the eastern margin of the landslide.

In order to investigate the frequencies amplified by the landslide, a series of single-station seismic noise measurements were performed during a reconnaissance field trip. They 


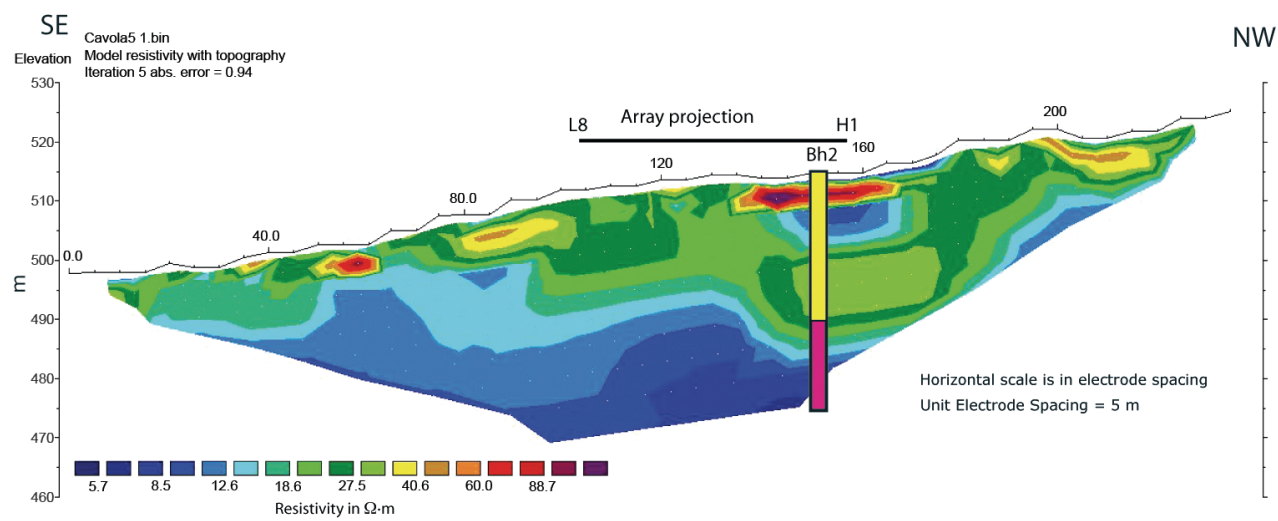

Fig. 6. $C$ - $C^{\prime}$ geo-electrical profile, showing the location of borehole 2 and array stations. See fig. 4 for the location of the profile.

are coded as CA5-CA8 in fig. 5, while measurements A3-D3-I3-M3-P3 were performed during the experiment and will be discussed in following paragraphs. The preliminary noise measurements analysis shows resonance in the frequency band $3-4.5 \mathrm{~Hz}$ with a systematic shift of the peak resonant frequencies which is linked to surface elevation, with the measurements at the highest elevations having the lowest peak frequencies. The simple inference from the correlation between high elevation and low peak frequency was that the landslide is thickest under the highest surface elevations.

We observed from preliminary noise measurements that the E-W component shows slightly higher horizontal to vertical spectral ratio than the N-S component. The difference between the E-W and N-S components seems unrelated to the surface topography which dips to the northeast.

Preliminary to the deployment of the seismic array, geo-electrical measurements were performed (fig. 4 for their location). Using a SyscalR2 resistivity meter (www.iris-instruments.com), we performed three multieletrodic surveys with 5 $\mathrm{m}$ uniform electrode spacing and a maximum length of $315 \mathrm{~m}$. Figure 6 shows the $C-C^{\prime}$ profile, the best one in resolving the shape of the landslide. Indeed, the multielectrical surveys do not provide a well-resolved geometry of the landslide although the quality of field data and of inversion is quite good (with less than $2 \%$ as the RMS difference between observed resistivity and the final inverted model). The low resolution in terms of resistivity results is due to the limited depth of investigation of our electric soundings, to the weak resistivity-contrast between the landslide body and the substratum, and to the complexity of topography that is not easily modelled by commercial software for geo-electrical inversion. The resistivity models show an average value of 20-30 $\Omega \cdot \mathrm{m}$ for the landslide body, typical of Italian clay marls. The underlying marls and shale (Monte Piano Formation) are characterised by lower values of resistivity $(\rho)$ of $5-10 \Omega \cdot m$ (fig. 6). Low values of $\rho$ for similar substratum have already been observed and explained in terms of clay content (Lollino et al., 2005). Another possible explanation could be linked to the presence of conductive fluid filling connected cracks in the basement Monte Piano Unit.

Notwithstanding the drawbacks described above, fig. 6 gave us information on the shape of the landslide body (matched by the $\rho$ 20-30 $\Omega \cdot \mathrm{m}$ body) suggesting that its thickness decreases down-hill (i.e. bottom of the array) and is about $25 \mathrm{~m}$ near the second borehole, borehole2. As we will see in the next paragraphs, this roughly agrees with borehole 2 and refraction profile $Z-Z^{\prime}$ and with the variation of the microtremor resonance frequency observed over the landslide. 


\section{Deployment of the seismic array}

As already discussed, the presence of landslide bodies superimposed on highly fracturated-low velocity bedrock is quite common in Northern Apennines. Many villages and small towns are built on such a geological setting, making the study of site response important both from practical and scientific purposes.

Since the morphology of landslides is quite complex, the site response analysis can be complicated with wave propagation involving 2D and $3 \mathrm{D}$ behaviour. Such a picture requires the use of a seismic array to detect short scale spatial changes in site response, to better understand the wavefront propagation through superficial layers and to study the level of correlation of seismic signal throughout the array. Ultimately, the very dense array geometry provides observations close enough for unambiguous comparison with numerical modelling.

Therefore, the array geometry was designed taking the following into consideration: the frequency range of amplified ground motion deduced by preliminary noise measurements; the available number of seismic stations; and the morphology and the logistic condition of the investigated area in relation to the available bedrock outcrops.

We deployed 95 instruments in a grid-like configuration (fig. 4). The station spacing was $10 \mathrm{~m}$ in the NE-SW direction, for a total length of $130 \mathrm{~m}$, and $8 \mathrm{~m}$ in the NW-SE direction, for a total width of $56 \mathrm{~m}$. The short NW-SE axis was approximately along strike of the topography, and in the perpendicular long direction there was $27 \mathrm{~m}$ of elevation change.

The minimum station spacing chosen avoids spatial aliasing for frequencies up to $20 \mathrm{~Hz}$ under the hypothesis of average shear wave velocities of around $350 \mathrm{~m} / \mathrm{s}$ in the landslide body. Such estimated velocities can be inferred from the resonance frequencies detected in the preliminary noise measurements linked to the bedrock depth derived from the existing borehole and from morphological considerations. In terms of slowness resolution the geometry permits us to work with minimum frequencies of around $1.5 \mathrm{~Hz}$ in the NE-SW direction, and of around $3 \mathrm{~Hz}$ in the NWSE direction (according to the lower limit of half a wavelength as explained in Wathelet et al., 2008). Given the resonance frequencies found in the preliminary noise measurements we can conclude that this resolution covers the frequency band of amplification except for waves travelling in the NW-SE direction. Unfortunately logistics limited the extension of the array in NW-SE direction to $56 \mathrm{~m}$.

We used Guralp CMG-6TD 3-component broadband seismometers provided by NERC SEIS-UK (based at the University of Leicester, http://www.le.ac.uk/seis-uk/equipment6t.htm). The instruments frequency response was much larger than required by the experiment, however the Guralp CMG-6TD suited our purpose exceptionally in terms of: i) small device dimension because the sensors, digitizer, and recording media are all packed together in a very small and light case; ii) low power consumption because data are written on 3 Gbyte RAM memory; iii) power supplied by small solar panels and backup batteries; iv) fast data retrieval by a USB interface connected to a palmtop PC.

A standard Huddle Test was performed on all the equipment for over $12 \mathrm{~h}$ before the field installation. The signals recorded allowed us to check the instruments for internal noise and instrumental failure. Only one of the 100 seismometers taken into the field could not be deployed, and the 95 best instruments in the Huddle Test were put into the array.

The seismic array operated between 19 July 2004 and 21 October 2004. The grid was established using an electronic geodimeter, posts were set and then a digger dug the holes in the places marked. At the bottom of each hole, between 70 and $100 \mathrm{~cm}$ deep, we placed a layer of sand to make it level, the sensor was put inside a plastic bag and then covered with sand to help the retrieval of the instruments. An USB cable connection reached the surface to allow fast data retrieval and instrument checking, including mass recentering, during periodic servicing. The relative position of each sensor was then recorded again using an electronic geodimeter. These positions were subsequently geo-referenced using 3 GPS portable stations deployed within the array area (visit the website http://legacy.ingv.it/ roma/reti/ rms/progetti/cavola/intro.htm where the deployment procedure is well documented). The data 
Table I. Earth model control sequence used for earthquake location in the program HYPOELLIPSE, with the ratio of the $P$-wave velocity to the $S$-wave velocity set equal to 1.80 . The upper crustal layer is $10 \mathrm{~km}$ thick and has $P$-wave velocity $5.0 \mathrm{~km} / \mathrm{s}$, the lower crustal layer is $20 \mathrm{~km}$ thick and has $P$-wave velocity $6.0 \mathrm{~km} / \mathrm{s}$, and the $P$-wave velocity in the upper mantle is $8.0 \mathrm{~km} / \mathrm{s}$.

\begin{tabular}{lll}
\hline \hline Header card & \multicolumn{2}{l}{ Mod. ING } \\
Crustal structure & 5.0 & 0.0 \\
Crustal structure & 6.0 & 10.0 \\
Crustal structure & 8.1 & 30.0 \\
Printer option & 0 & \\
Punch option & -1 & \\
Quality option & 0 & \\
Reset test & 1 & 1.80 \\
Reset test & 7 & 1000. \\
Reset test & 8 & 1000. \\
Reset test & 9 & 360. \\
Reset test & 10 & 1. \\
Reset test & 11 & 70. \\
Reset test & 12 & 500. \\
Reset test & 13 & 50. \\
Reset test & 14 & 3. \\
Reset test & 18 & 3. \\
Reset test & 21 & 15. \\
Reset test & 38 & 2. \\
\hline
\end{tabular}

sample rate was set to 200 samples/s for the first recording period (15 days), then modified to 100 samples/s for the remainder of the experiment.

In addition, 3 extra Guralp CMG-6TD were installed in private houses in Cavola village (CA, $\mathrm{OR}, \mathrm{SC}$, fig. 4) to study seismic response in the more inhabited area of the landslide, and one deployed in the Madonna della Neve Church $(\mathrm{CH})$ on the Ranzano Formation enabling study of the response of all the available bedrock-like units. The same data sample rates as for the instruments in the array were set throughout the experiment. Two more seismographs, equipped with Reftek 72A data loggers and Lennartz LE-3D (5 s) extended band sensors, were running throughout the experiment and they were located in bedrock conditions at the CA9 site on the Monte Piano Formation and in a site close to the borehole1 indicated as ORTO site in fig. 4. For these two stations the sample rate was set to 125 samples/s.

\section{Microearthquake network}

A microearthquake network (fig. 3, bottom) was deployed in the vicinity of the Cavola array throughout the experiment, both to reduce the detection threshold and to improve on the quality of location of small magnitude local earthquakes by INGV national seismic network (Rete Sismica

Table II. List of earthquakes recorded during the experiment.

\begin{tabular}{lccc|cccc}
\hline \hline & Earthquake & Lat & Long & & Earthquake & Lat & Long \\
\hline 1 & $15 / 07 / 200423: 29: 58.9000$ & 44.26 & 10.22 & 14 & $25 / 07 / 200405: 34: 42.1500$ & 44.00 & 10.74 \\
2 & $16 / 07 / 200414: 23: 19.7500$ & 44.49 & 10.24 & 15 & $25 / 07 / 200407: 44: 00.5500$ & 44.01 & 10.62 \\
3 & $17 / 07 / 200417: 33: 42.2200$ & 44.14 & 10.5 & 16 & $25 / 07 / 200417: 07: 12.1300$ & 44.32 & 10.09 \\
4 & $18 / 07 / 200402: 01: 40.1500$ & 44.32 & 10.69 & 17 & $27 / 07 / 200403: 26: 57.6000$ & 44.14 & 10.17 \\
5 & $18 / 07 / 200402: 22: 39.1800$ & 44.35 & 10.67 & 18 & $28 / 07 / 200404: 43: 26.3300$ & 44.28 & 10.67 \\
6 & $19 / 07 / 200422: 24: 55.2700$ & 44.66 & 9.45 & 19 & $29 / 07 / 200401: 25: 26.1800$ & 44.52 & 9.83 \\
7 & $22 / 07 / 200416: 27: 15.2500$ & 44.24 & 11.08 & 20 & $29 / 07 / 200406: 54: 48.2500$ & 44.86 & 10.79 \\
8 & $23 / 07 / 200401: 26: 05.7800$ & 43.44 & 12.42 & 21 & $29 / 07 / 200421: 26: 43.0300$ & 44.34 & 10.98 \\
9 & $23 / 07 / 200404: 23: 27.4400$ & 44.11 & 10.85 & 22 & $30 / 07 / 200400: 58: 08.0800$ & 44.2 & 10.63 \\
10 & $23 / 07 / 200409: 32: 01.4400$ & 44.24 & 10.86 & 23 & $30 / 07 / 200401: 03: 27.2200$ & 44.08 & 10.69 \\
11 & $23 / 07 / 200413: 52: 05.7000$ & 46.36 & 13.68 & 24 & $30 / 07 / 200407: 26: 08.8200$ & 44.17 & 10.44 \\
12 & $23 / 07 / 200418: 11: 24.7700$ & 44.50 & 09.66 & 25 & $31 / 07 / 200422: 57: 36.4600$ & 44.19 & 11.92 \\
13 & $24 / 07 / 200408: 53: 38.9800$ & 44.45 & 10.62 & 26 & $01 / 08 / 200410: 06: 06.2700$ & 44.42 & 10.04 \\
\hline
\end{tabular}


Table II (continued).

\begin{tabular}{|c|c|c|c|c|c|c|c|}
\hline & Earthquake & Lat & Long & & Earthquake & Lat & Long \\
\hline 27 & 01/08/2004 11:06:26.6500 & 44.46 & 9.94 & 68 & 22/08/2004 22:49:41.5800 & 44.4 & 10.75 \\
\hline 28 & 01/08/2004 14:57:06.8100 & 44.3 & 10.85 & 69 & 23/08/2004 01:20:45.8900 & 44.32 & 10.82 \\
\hline 29 & 01/08/2004 22:45:44.6700 & 43.95 & 10.64 & 70 & 23/08/2004 15:56:43.3800 & 4.47 & 10.8 \\
\hline 30 & 02/08/2004 18:44:44.1500 & 44.58 & 9.39 & 71 & 23/08/2004 20:42:19.5100 & 44.2 & 10.18 \\
\hline 31 & 02/08/2004 19:25:15.3100 & & 9.34 & 72 & 24/08/2004 01:26:38.9100 & & 10.79 \\
\hline 32 & 03/08/2004 01:13:02.1000 & 44.59 & 9.45 & 73 & 24/08/2004 01:27:23.5300 & 44.37 & 10.82 \\
\hline 33 & 03/08/2004 07:48:05.5300 & 45.51 & 10.25 & 74 & 24/08/2004 01:33:27.3100 & 44.33 & 10.83 \\
\hline 34 & 03/08/2004 23:35:57.1300 & 44.53 & 8.71 & 75 & 24/08/2004 01:36:52.5900 & 44.37 & 10.82 \\
\hline 35 & 04/08/2004 00:45:24.3900 & 44.31 & 10.08 & 76 & 24/08/2004 01:38:47.9400 & 44.37 & 10.82 \\
\hline 36 & 04/08/2004 14:17:40.3100 & 44.33 & 11.27 & 77 & 24/08/2004 08:12:48.1600 & 44.35 & 10.99 \\
\hline 37 & 05/08/2004 03:13:33.7200 & 44.44 & 10.74 & 78 & 24/08/2004 09:09:26.7400 & 44.28 & 11.01 \\
\hline 38 & 05/08/2004 09:04:49.8300 & 44.43 & 10.74 & 79 & 24/08/2004 14:57:52.1100 & 45 & 9.92 \\
\hline 39 & 05/08/2004 10:47:18.3200 & 44.2 & 10.73 & 80 & $24 / 08 / 2004$ & 44.17 & 10.22 \\
\hline 40 & 06/08/2004 06:29:29.4900 & 44.43 & 10.52 & 81 & 25/08/2004 20:07:07.3100 & 44.29 & 10.97 \\
\hline 41 & 06/08/2004 10:40:30.1400 & 44.34 & 10.83 & 82 & 26/08/2004 21:24:01.9600 & 44.4 & 9.84 \\
\hline 42 & 06/08/2004 13:11 & & 9.84 & 83 & 27/08/2004 00:1 & 46.21 & 12.42 \\
\hline 43 & 06/08/2004 16:36:34.0900 & 44.44 & 10.52 & 84 & 27/08/2004 17:47:04.2100 & 44.18 & 10.25 \\
\hline 44 & 08/08/2004 06:09:57.4200 & 44.14 & 10.54 & 85 & 27/08/2004 21:47:35.3600 & 44.16 & 10.2 \\
\hline 45 & 08/08/2004 18:48:06.2200 & 44.3 & 10.97 & 86 & $27 /($ & 18 & 10.23 \\
\hline 46 & 09/08/2004 19:35:58.4000 & 44.64 & 10.39 & 87 & 27/08/2004 22:16 & 14 & 10.2 \\
\hline 47 & 10/08/2004 13:38:42.8500 & 43.95 & 10.71 & 88 & 27/08/2004 22:17:20.3700 & 17 & 10.27 \\
\hline 48 & 11/08/2004 00:10:45.0400 & & & 89 & 27/08/2004 23:26 & 44.18 & 10.23 \\
\hline 49 & 11/08/2004 00:10:44.8200 & 44.42 & 10.53 & 90 & 000 & 46.4 & 12.89 \\
\hline 50 & 11/08/2004 00:11:41.3000 & & & 91 & & & 12.9 \\
\hline 51 & 13/08/2004 21:42:56.3900 & 44.92 & 11.03 & 92 & 29/08/2004 02:14 & & 10.24 \\
\hline 52 & 14/08/2004 12:21:41.5200 & 44.26 & 10.18 & 93 & 29/08/2004 02:44:32.8700 & 44.48 & 10.05 \\
\hline 53 & 14/08/2004 12:22:41.7700 & 44.3 & 10.23 & 94 & 29/08/2004 13:40:58.8800 & 44.36 & 10.87 \\
\hline 54 & 15/08/2004 02:01:35.5500 & 44.82 & 10.62 & 95 & 29/08/2004 13:41:20.1300 & 44.31 & 10.94 \\
\hline 55 & 15/08/2004 04:41:38.2200 & 43.08 & & 96 & 29/08/2004 14:47:53.1600 & 44.21 & 10.2 \\
\hline 56 & 16/08/2004 01:37:06.3000 & 44.29 & 10.21 & 97 & 29/08/2004 18:39:26.1900 & 43.87 & 11.96 \\
\hline 57 & 16/08/2004 05:58:21.3300 & 44.31 & 9.94 & 98 & 03/09/2004 1 & & 10.89 \\
\hline 58 & 16/08/2004 22:32:54.3100 & 44.22 & 10.11 & 99 & 04/09/2004 19:35:33.6000 & 44.03 & 11.94 \\
\hline 59 & 17/08/2004 10:58:24.9700 & 44.18 & 10.5 & 100 & 04/09/2004 19:47:29.0600 & 44.05 & 11.99 \\
\hline 60 & 17/08/2004 11:15:40.7800 & 44.56 & 9.24 & 101 & 04/09/2004 21:50:51.5400 & 44.02 & 11.98 \\
\hline 61 & 17/08/2004 11:17:03.7700 & 44.64 & 9.41 & 102 & 05/09/2004 04:17:38.4400 & 44.04 & 12.02 \\
\hline 62 & 19/08/2004 18:00:46.6200 & 44.99 & 11.93 & 103 & 05/09/2004 04:37:09.0800 & 44.02 & 11.98 \\
\hline 63 & 21/08/2004 14:12:47.8500 & 44.27 & 11.61 & 104 & 06/09/2004 03:30:25.2200 & 44.38 & 10.77 \\
\hline 64 & 22/08/2004 07:13:46.2500 & 44.2 & 10.72 & 105 & 07/09/2004 00:57:45.6000 & 44.03 & 12.03 \\
\hline 65 & 22/08/2004 18:35:17.6200 & 44.5 & 10.8 & 106 & 07/09/2004 00:58:37.0200 & 44.17 & 12.13 \\
\hline 66 & 22/08/2004 19:48:22.8800 & 44.38 & 10.74 & 107 & 07/09/2004 07:15:12.8100 & 44.7 & 7.66 \\
\hline 67 & 22/08/2004 22:01:39.9700 & 45.02 & 11.19 & 108 & 09/09/2004 12:26:50.7700 & 44.24 & 10.19 \\
\hline
\end{tabular}


Table II (continued).

\begin{tabular}{cccc|cccc}
\hline \hline & Earthquake & Lat & Long & & Earthquake & Lat & Long \\
\hline 109 & $10 / 09 / 2004$ 04:46:36.3700 & 44.25 & 10.76 & 127 & $26 / 09 / 200419: 56: 55.6100$ & 44.43 & 10.18 \\
110 & $10 / 09 / 2004$ 05:40:48.3400 & 44.35 & 10.57 & 128 & $28 / 09 / 200407: 09: 30.3000$ & 44.43 & 10.65 \\
111 & $11 / 09 / 2004$ 09:00:43.6600 & 44.94 & 11.29 & 129 & $28 / 09 / 200421: 17: 29.8600$ & 44.16 & 10.64 \\
112 & $11 / 09 / 2004$ 09:04:02.0700 & 44.96 & 11.19 & 130 & $30 / 09 / 200420: 42: 43.7400$ & 44.16 & 10.5 \\
113 & $11 / 09 / 200413: 20: 03.3800$ & 44.92 & 10.71 & 131 & $30 / 09 / 200420: 44: 08.2200$ & 44.23 & 10.51 \\
114 & $11 / 09 / 2004 ~ 23: 19: 13.2200$ & 44.25 & 10.82 & 132 & $01 / 10 / 200403: 11: 51.2500$ & 44.59 & 9.95 \\
115 & $14 / 09 / 200418: 09: 23.4800$ & 45.37 & 14.77 & 133 & $04 / 10 / 200404: 22: 01.8800$ & 44.1 & 10.67 \\
116 & $19 / 09 / 2004 ~ 01: 18: 54.3200$ & 44.13 & 10.21 & 134 & $07 / 10 / 200419: 21: 41.3700$ & 43.82 & 10.75 \\
117 & $19 / 09 / 200404: 22: 34.1800$ & 44.14 & 10.25 & 135 & $07 / 10 / 200420: 32: 18.1700$ & 44.41 & 12.13 \\
118 & $19 / 09 / 200412: 38: 36.8500$ & 44.29 & 10.8 & 136 & $08 / 10 / 200406: 07: 36.7300$ & 44.34 & 10.68 \\
119 & $21 / 09 / 200410: 51: 04.2200$ & 44.99 & 9.35 & 137 & $08 / 10 / 200419: 01: 05.2100$ & 44.1 & 12.2 \\
120 & $21 / 09 / 200418: 29: 16.8500$ & 44.12 & 10.97 & 138 & $09 / 10 / 200400: 02: 58.2300$ & 44.4 & 11.15 \\
121 & $22 / 09 / 200401: 22: 17.4700$ & 44.36 & 10.8 & 139 & $09 / 10 / 200404: 18: 43.2100$ & 44.38 & 11.16 \\
122 & $22 / 09 / 200423: 48: 44.5400$ & 44.39 & 10.64 & 140 & $11 / 10 / 200410: 58: 42.8100$ & 43.78 & 10.78 \\
123 & $23 / 09 / 200417: 40: 32.7100$ & 44.51 & 10.56 & 141 & $11 / 10 / 200411: 24: 54.0300$ & 44.1 & 12.23 \\
124 & $24 / 09 / 200415: 25: 51.8400$ & 44.48 & 10.56 & 142 & $14 / 10 / 200404: 13: 04.9800$ & 44.19 & 10.94 \\
125 & $24 / 09 / 200422: 09: 03.0000$ & 44.51 & 10.65 & 143 & $19 / 10 / 200423: 58: 25.2200$ & 44.18 & 10.19 \\
126 & $24 / 09 / 200422: 44: 50.7900$ & 44.58 & 10.59 & 144 & $20 / 10 / 200400: 12: 58.5200$ & 44.21 & 10.81 \\
\hline
\end{tabular}

Nazionale Centralizzata, RSNC). Indeed, at the time of the experiment, the RSNC detection threshold for local events very close to the Cavola site was estimated to be at best $M l 2.0$.

The microearthquake network comprised 5 portable Reftek 130 receivers coupled with Lennartz seismometers (Le-3D Lite, $1 \mathrm{~Hz}$ ), that, combined with RSNC instruments, set the interstation distance at about $10 \mathrm{~km}$ around the Cavola array. Temporary local stations were hence very useful to locate small events, while the largest events were located using both local and regional stations. The location was performed using the HYPOELLIPSE program (Lahr, 1999). Table I summarises the propagation model used, table II lists the detected earthquakes, fig. 3 (bottom) shows the location of events.

\section{New borehole and down-hole measurements}

During the experiment a second borehole, borehole2, was drilled inside the seismic array area (fig. 4 for its location). The pre-existing borehole1, to the west and less than $50 \mathrm{~m}$ from the array, is at a similar surface elevation to the highest points of the array along line A, whereas borehole 2 is halfway down the array between lines $G$ and $H$. Like borehole1, borehole2 reached the bedrock, which again was logged as Monte Piano Formation (fig. 7). The stratigrahic core extracted shows $22 \mathrm{~m}$ of landslide deposit and $3 \mathrm{~m}$ of debris deposit. At borehole1, located at $532 \mathrm{~m}$ of elevation, the depth to the bedrock is $44 \mathrm{~m}$ which gives $488 \mathrm{~m}$ of elevation above sea level for bedrock, while at borehole2, located at $516 \mathrm{~m}$ of elevation, the depth to the bedrock is $25 \mathrm{~m}$ which gives $491 \mathrm{~m}$ of elevation above sea level for bedrock. Hence, the landslide thickness in the two boreholes is significantly different: larger thickness of landslide deposits with higher surface elevation agrees with the inference from preliminary seismic noise measurements.

The bedrock at borehole 2 is $3 \mathrm{~m}$ higher than in borehole1. The height difference could suggest the presence of a tectonic element between 


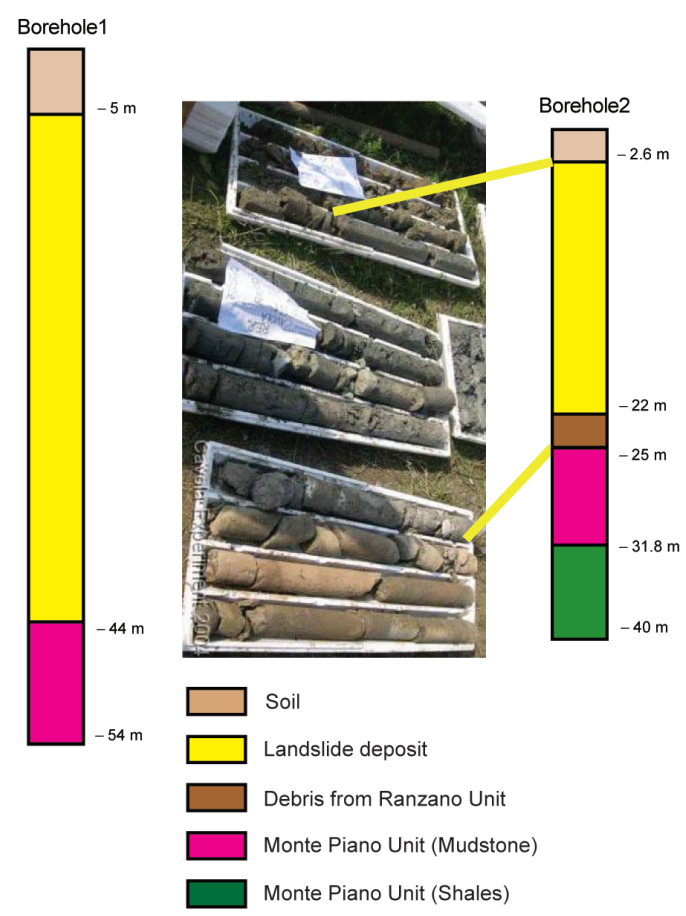

Fig. 7. Borehole logs: borehole1 was an existing borehole, while borehole2 was drilled during the experiment. Photograph of the core from borehole2. The light brown unit at the top of each log is soil, essentially part of the landslide body but containing organics, the landslide body proper is yellow, the underlying debris layer is shown both as dark brown, the magenta layer is the top of the Monte Piano basement (Mudstone), and the green is the Shale unit of the Monte Piano basement. the boreholes or it could be the effect of processes involved in the landsliding.

At borehole2 down-hole $P$ - and $S$-wave travel times were logged by Sezione di Geotecnica, Dipartimento di Ingegneria Civile, Università degli Studi di Firenze. Figure 8 shows the first-pulse travel times as well as the corresponding profiles of average $V s$ and $V p$ values down to each depth. The inferred interval values of $P$-wave velocity are $520 \mathrm{~m} / \mathrm{s}$ in the top $3 \mathrm{~m}$ above the water table, $1630 \mathrm{~m} / \mathrm{s}$ in the body of the landslide, and 2850 $\mathrm{m} / \mathrm{s}$ in the basement. For $S$-waves inferred interval velocities are $230 \mathrm{~m} / \mathrm{s}$ and $625 \mathrm{~m} / \mathrm{s}$ above the water table and in the basement respectively, while in the landslide below the water table the $S$-wave velocity increased approximately linearly with depth from about $300 \mathrm{~m} / \mathrm{s}$ at the top to a value very close to that in the basement at the bottom. The increase in $S$-wave velocity with depth inside the landslide is indicative of a corresponding increase in compaction of the landslide deposits due to gravitational (lithostatic) loading, whereas the comparatively constant $P$-wave velocity of 1630 $\mathrm{m} / \mathrm{s}$ is indicative of a high degree of water saturation. The $V p / V s$ ratio for the Monte Piano Formation (bedrock) can be explained in terms of saturation of the cracked basement.

\section{Seismic refraction lines and surface wave analyses}

To complement the down-hole measurements, two conventional $P$-wave seismic refrac-
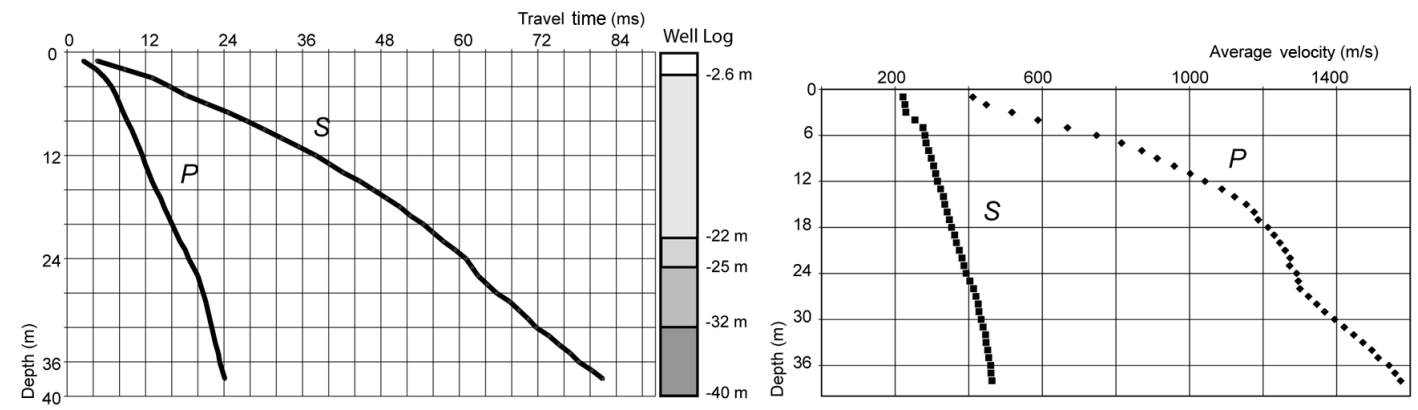

Fig. 8. Left: vertical travel times of $P$ and $S$ waves at borehole2. Right: profiles of average velocities to each depth for $P$ and $S$ waves. 

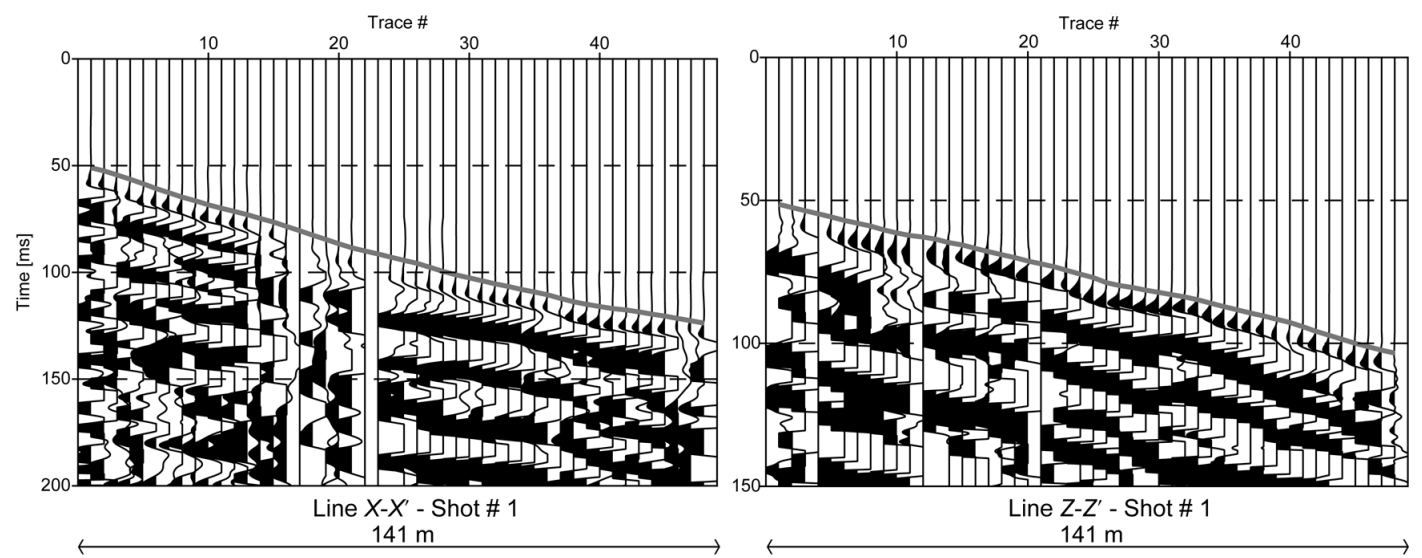

Fig. 9. Example of shot 1 records for line $X-X^{\prime}$ (left) and line $Z-Z^{\prime}$ (right).
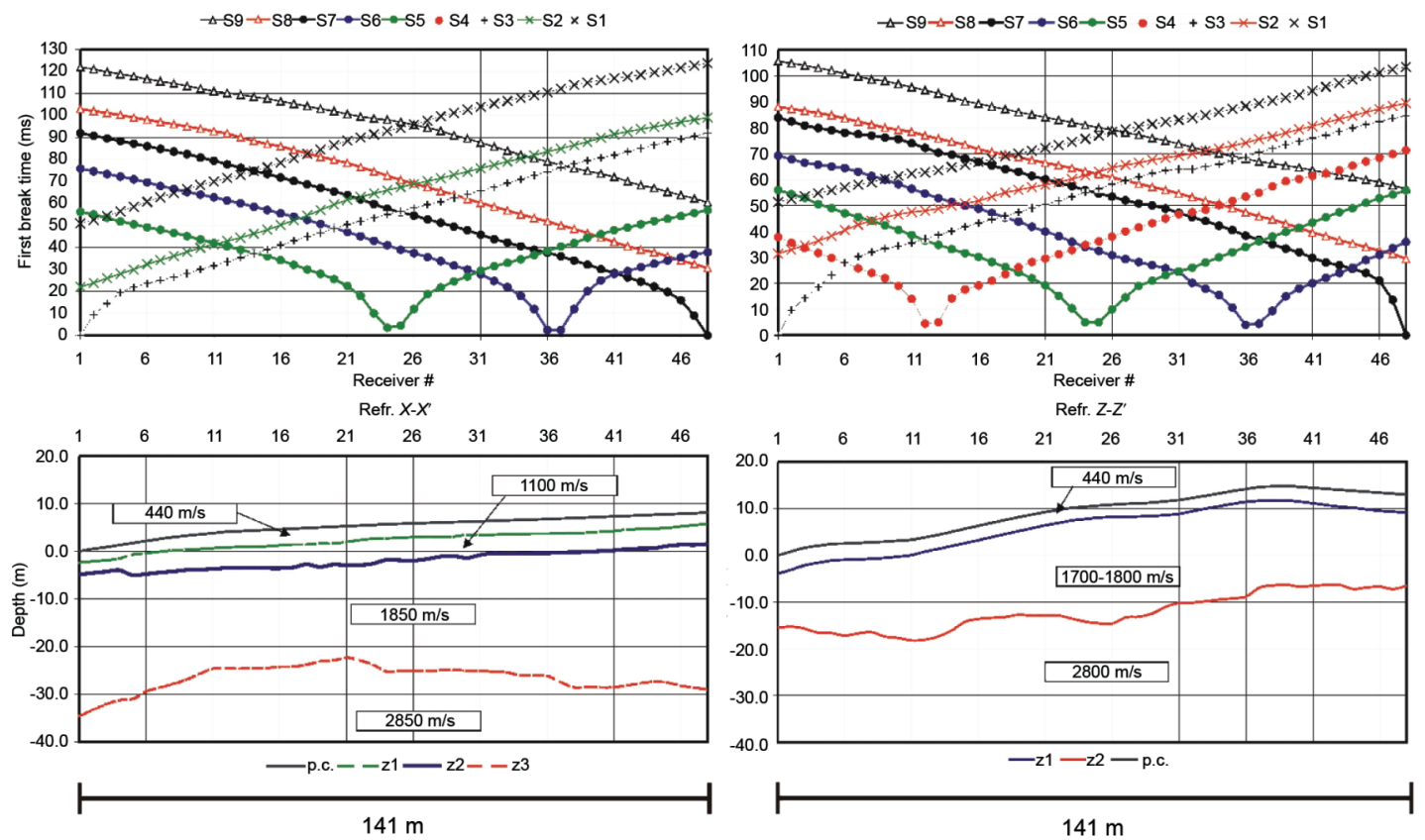

Fig. 10. Results of conventional $P$-wave refraction along lines $X$ - $X^{\prime}($ left $)$ and $Z-Z^{\prime}($ right).

tions profiles were acquired during the experiment adjacent to boreholes 1 and 2 (fig. 4 for location of their traces $X-X^{\prime}$ and $\left.Z-Z^{\prime}\right)$. Line $X-X^{\prime}$ was re-acquired in November 2006 with a longer extension.
In addition to $V p$ analysis, the recorded data were processed using the Multichannel Analysis of Surface Waves (MASW) technique for line $Z-Z^{\prime}$ and also the Noise Analysis of Surface Waves (NASW) technique for line $X-X^{\prime}$. 
Data were acquired using Geometrics multichannel geode and $4.5 \mathrm{~Hz}$ vertical geophones.

On the first survey, refraction lines consisted of 48 receivers spaced $3 \mathrm{~m}$ apart, and the seismic waves were generated using a «Minibang» source. Nine shots were executed with a maximum offset of $70 \mathrm{~m}$ for both lines. Recordings consist of 16384 time samples at $0.125 \mathrm{~ms}$ interval.

Example seismograms for lines $X-X^{\prime}$ and $Z$ $Z^{\prime}$ are displayed in fig. 9 for shot 1 in each case. Selected first arrivals were interpreted using the delay method for shallow targets (Bernabini, 1965). From the travel-time curves, three seismic layers were detected and the associated delay times for each geophone were calculated with an estimated uncertainty of about $1 \mathrm{~ms}$. The entire set of time-distance curves is reported in fig. 10 together with the interpreted velocity profiles for lines $X-X^{\prime}$ (top) and $Z-Z^{\prime}$ (bottom). As few first arrivals for line $X-X^{\prime}$ are related to the deeper refractor, that refractor is displayed using a dashed line, since it is partially interpolated.

Both profiles identify a thin low velocity surface layer above a faster unit with $P$ waves velocity ranging from 1700 to $1850 \mathrm{~m} / \mathrm{s}$. These two layers comprise the landslide body overlying the bedrock characterized by a $V p$ velocity of $2800-2850 \mathrm{~m} / \mathrm{s}$. Bedrock depth ranges between 30 and $39 \mathrm{~m}$ and 15 and $25 \mathrm{~m}$ for lines $X$ $X^{\prime}$ and $Z-Z^{\prime}$ respectively. In particular for the central part of line $Z-Z^{\prime}$, corresponding to the array area, bedrock depth is in the $20-25 \mathrm{~m}$ range in agreement with the borehole 2 result. The $V p$ model for line $Z-Z^{\prime}$ matches roughly the thickness of clay deposits estimated from the geo-electrical line $C$ - $C^{\prime}$ (fig. 6). Bedrock depths inferred for line $X-X^{\prime}$ are shallower than that found in borehole 1, particularly between geophones 10 and 20. In this case, first-arrivals in off-end shots $S 1$ and $S 9$ are only partly related to the deeper refractor, and the bedrock reconstruction could not be as precise as for line $Z-Z^{\prime}$.

The refraction line data were also used for surface wave analysis (MASW-NASW). We retrieved dispersion curves for lines $X-X^{\prime}$ and $Z-Z^{\prime}$ (fig. 11, upper panel) using three different software programs: Remi (Louie, 2001), INGV and Sesame (2001-2004) softwares based on $f-k$
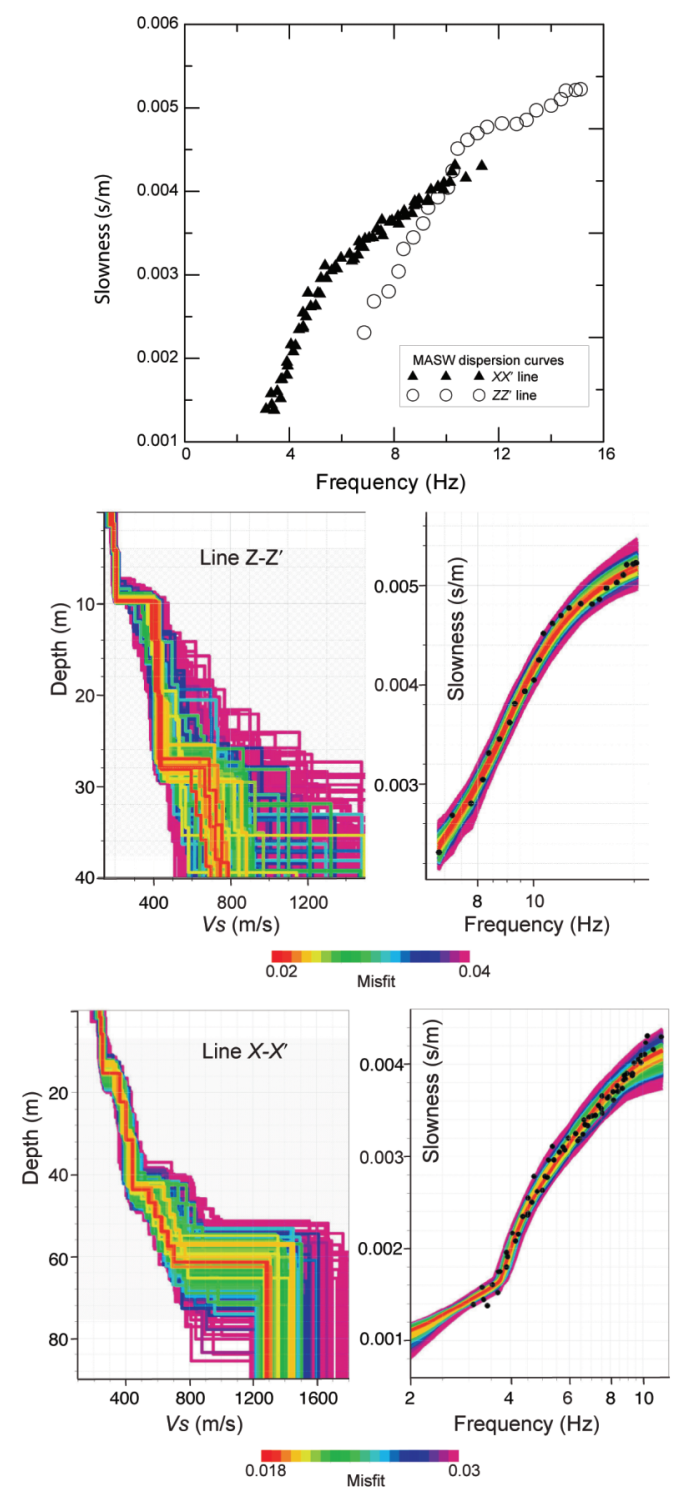

Fig. 11. Dispersion curves are shown for lines $X-X^{\prime}$ and $X-X^{\prime}$ (upper panel). Velocity profiles obtained from the inversion of the upper panel dispersion curves (middle and lower panels). The color scale is proportional to the misfit carried out by the inversion. Mean depths to basement inferred are $28 \mathrm{~m}$ for line $X-X^{\prime}$ and $44 \mathrm{~m}$ for line $X-X^{\prime}$ (middle and lower panel respectively). These are in good agreement with the depths to basement in boreholes 2 and 1 respectively and with the depths to basement along line $X-X^{\prime}$, in particular, from the $P$-wave refraction. 
analysis (Capon, 1969). Such dispersions curves were then inverted using the inversion software Geopsy based on a neighbourhood algorithm (http://www.geopsy.org, Wathelet, 2005). The results of the inversion are the one-dimensional (1D) shallow shear-velocity profiles showed in fig. 11 (middle and lower panels).

For line $Z-Z^{\prime}$ the explosive sources proved adequate, resulting in dispersion curves that constrain the acceptable velocity-depth profiles to a tightly defined set, particularly at shallow depths. The inferred depth of $28 \mathrm{~m}$ to the basement obtained with the inversion (fig. 11, middle panel) agrees broadly with the depths to basement along the $P$-wave refraction profile.

For line $X-X^{\prime}$ both the deployment geometry and the high frequency content of the minibang source did not allow us to detect the basement position and the result is not shown. To overcome this problem an extra set of measurements was collected along the $X-X^{\prime}$ trace, with 72 channels and $4.5 \mathrm{~Hz}$ vertical geophones at 4 $\mathrm{m}$ spacing, for a total length of $284 \mathrm{~m}$. We recorded both active and passive data. In order to enrich the recorded signals with low frequencies, which were lacking in the first survey, we choose a bigger active source, a huge agricultural tractor, moving at a distance of about $50 \mathrm{~m}$ from the array ends. As passive source we recorded seismic microtremor data. This time, the dispersion curves were obtained through a combination of the MASW and NASW techniques. The inversion of the composite dispersion curve is the $X-X^{\prime}$ shear-velocity profiles shown in fig. 11 (lower panel), which give $44 \mathrm{~m}$ as most likely depth to basement, in agreement with the depth at borehole1.

$X-X^{\prime}$ and $Z-Z^{\prime}$ dispersion curves show comparable values of apparent slowness for frequency higher than $10 \mathrm{~Hz}$ (fig. 11, upper panel), which in turn means that very shallow layers are characterized by similar $V s$ velocities. These dispersion curves have steps at about 6 and $10 \mathrm{~Hz}$ respectively, tied to depth where the bedrock influence starts.

The shear velocity profiles inverted for lines $X-X^{\prime}$ and $Z-Z^{\prime}$ (fig. 11, middle and lower panels) show, in terms of thickness and velocity, consistent values with the down-hole and refraction analysis. A point to note is that the apparent step- like character of the velocity-depth profiles is an artefact of how they are selected during the inversion process, and an approximately linear increase of $S$-wave velocity within the landslide body is more likely (as indicate by down-hole measurements). The unit estimated for line $X-X^{\prime}$ at about $60 \mathrm{~m}$ shows large $S$-wave values (1200$1500 \mathrm{~m} / \mathrm{s}$ ) and could suggest a stiff deeper layer. This inferred deeper bedrock layer is very poorly constrained by surface wave analysis, as is indicated by the fluctuation of the dispersion curve at the lowest frequencies for line $X$ - $X^{\prime}$ (fig. 11, lower panel). In general, the resolution of the inverted $V s$ profiles decreases for depths within basement for both lines. This is partly because the surface wave analysis uses the vertical component of Rayleigh waves, whose energy content relative to the horizontal component decreases approaching the resonance frequency.

Overall the comparison between down-hole, refraction and surface wave analysis results shows good consistency in both the depths and the velocities estimated. All the differences can be readily explained by considering the differences in the approaches used, with down-hole giving point values, surface wave analysis giving spatial averages based on 1D approximation, and refraction fully $2 \mathrm{D}$ results.

\section{Seismic data recorded by the array}

All the stations operated continuously for three months, recording 900 Gbyte of data. 145 local and regional earthquakes with good signal-to-noise ratios were identified and located, with magnitudes up to 4.5 and epicentral distances ranging between $3 \mathrm{~km}$ and $350 \mathrm{~km}$ (fig. 3 , bottom).

Figures 12 and 13 show example recordings of a teleseismic event and a local earthquake along NE-SW line 3 in the array. This line ran from the high point of the array down to the bedrock site P3 in the stream bed at the bottom of the array. For the teleseismic event (fig. 12, top) many separate wave phases can be discerned, representing different ray paths through the Earth. The largest arrivals are surface waves. The waveforms on the E-W, N-S and vertical components are quite different. The waveforms for each 
Teleseismic event: 05/09/2004 14:57:18.6100, Mb 7.4, Depth 10 km
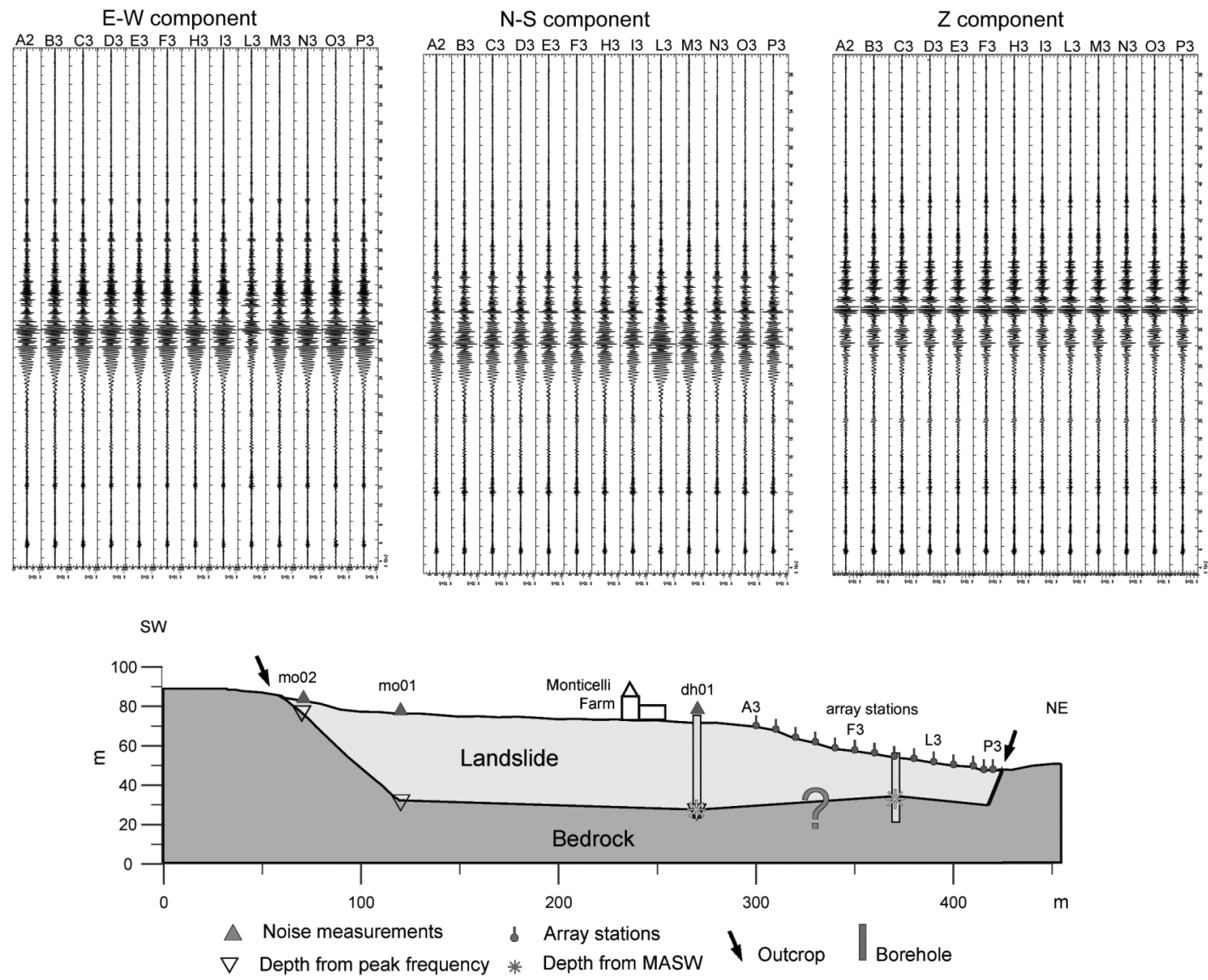

Fig. 12. Top: examples of recordings along NE-SW array line 3 from a teleseismic event $(M=7.4,5$ September 2004 14:57:18.6, from Honshu, Japan) the recordings have been decimated by a 10 factor from the original sample rate of $100 \mathrm{~Hz}$. Bottom: a 2D model of the landslide reconstructed using all the data collected.

component are extremely similar along the array due to the large wavelength of teleseismic signals which are not affected by the small scale heterogeneity associated with the landslide.

In contrast, in the recordings of the local earthquake (fig. 13) shorter wavelengths are more sensitive to small-scale variation within the propagating medium, making the correlation between the signals much lower. Again there are very clear differences between the tangential and the radial components, and again there are several different wave packets visible. In this case, however, the waveforms vary markedly in amplitude and shape across the array due to the presence of the landslide. This variability, which is most marked in the tangential components, suggests an important role of locally generated surface waves.

Figure 13 shows recordings along the array line 3, with the B3 station at the top of the array area and the bedrock P3 station at the bottom of the array area. The largest ground motion amplitude is shown by stations F3 to M3 in the middle part of the array where the topography is nearly flat. In addition, because the local earthquake in 
Local event: 2004/08/27 21:47 MI 3.7 Backazimuth=225
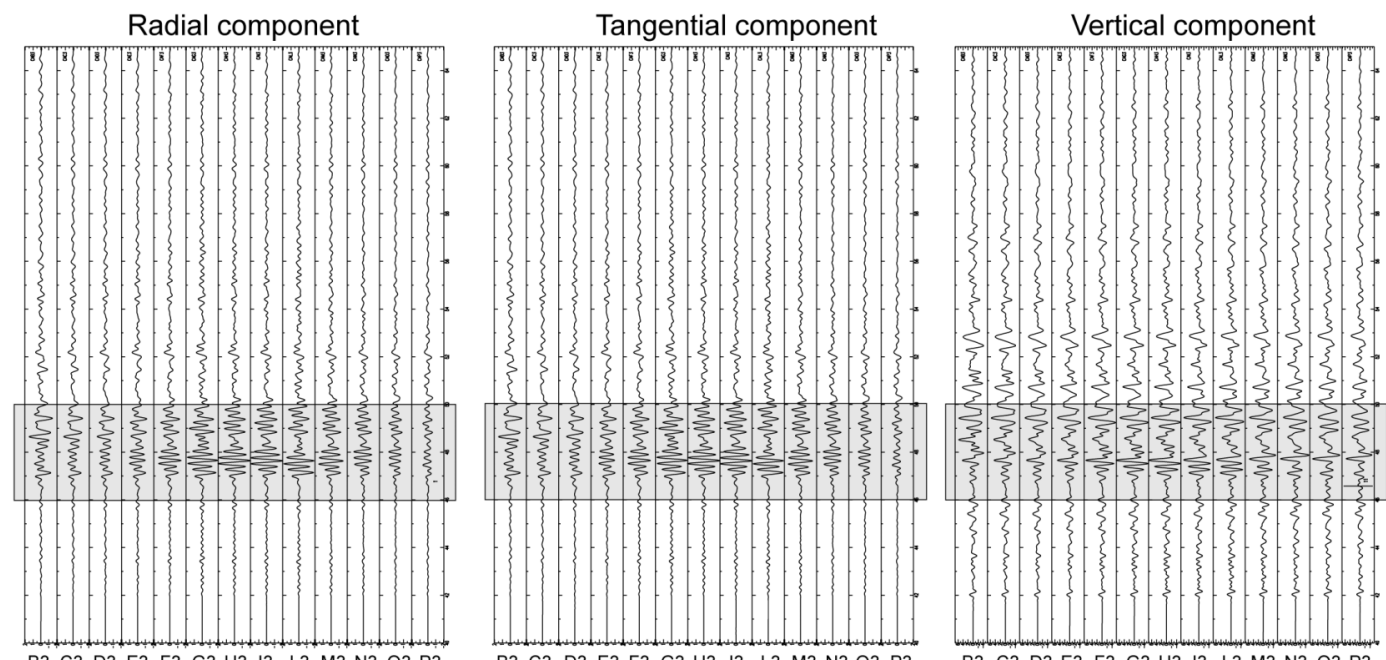

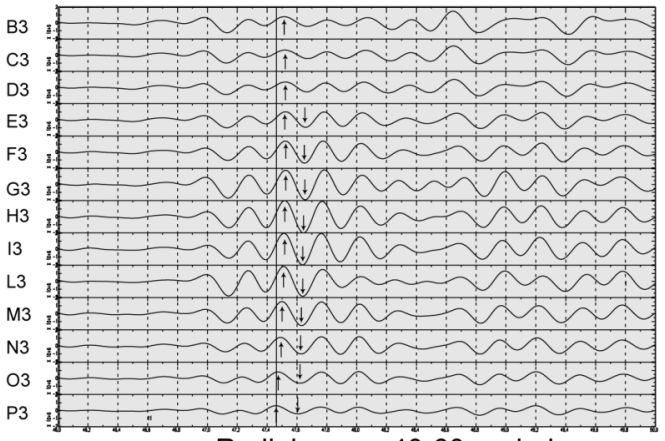

Radial comp. 40-60 s window

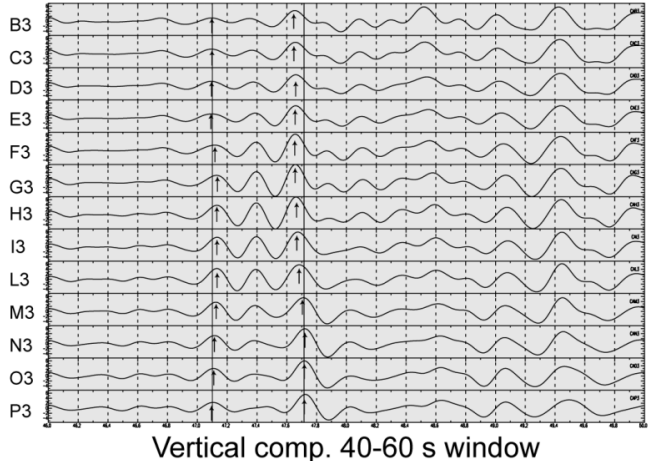

Vertical comp. 40-60 s window

Fig. 13. Top: examples of recordings along NE-SW array line 3 from local earthquake $(M=3.7,27$ August 2004 21:47:00, southwest of the array). The recordings of the local earthquake have been bandpass filtered between $0.5 \mathrm{~Hz}$ and $10 \mathrm{~Hz}$. Bottom: zoom of a $20 \mathrm{~s}$ window and outlining of wave packets travelling in the reverse direction.

fig. 13 occurred southwest of the array (back-azimuth 225) it should be travelling from B3 (SW) to P3 (NE) in a homogenous media. Interestingly, some of the wave packets can be identified to be travelling in the reverse direction (highlighted with arrows in the radial and vertical blow up pictures). In part, this may just reflect the delay the waves experience due to the higher surface elevation and greater thickness of landslide at the southwest end of the line. On the other hand, waves are expected to be diffracted back from the eastern margin of the landslide, and wave packets that appear to arrive from directions other than the earthquake are very common among the recordings of local and regional events. It is likely that these waves originate either within the landslide or from nearby topography.

\section{Seismic noise measurements from the array and the surrounding area}

Figure 14 shows microtremor data analysis from station recordings performed within and 

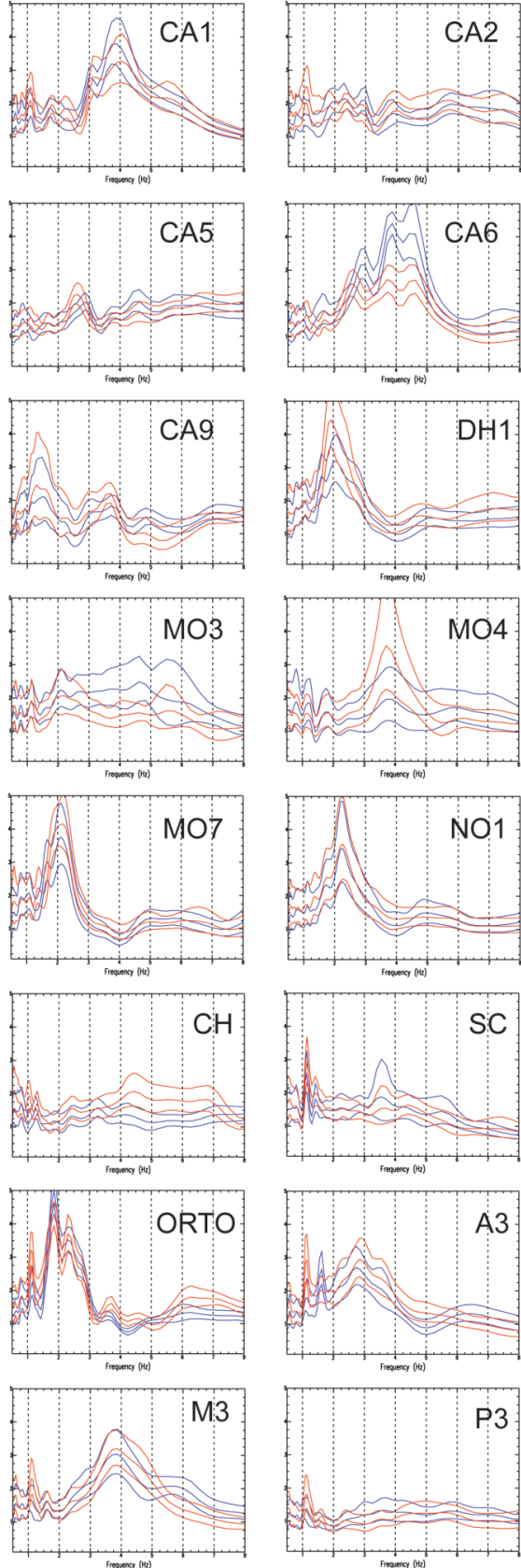

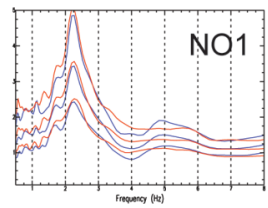

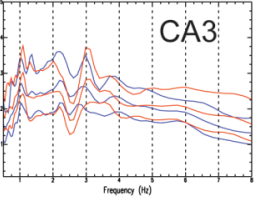
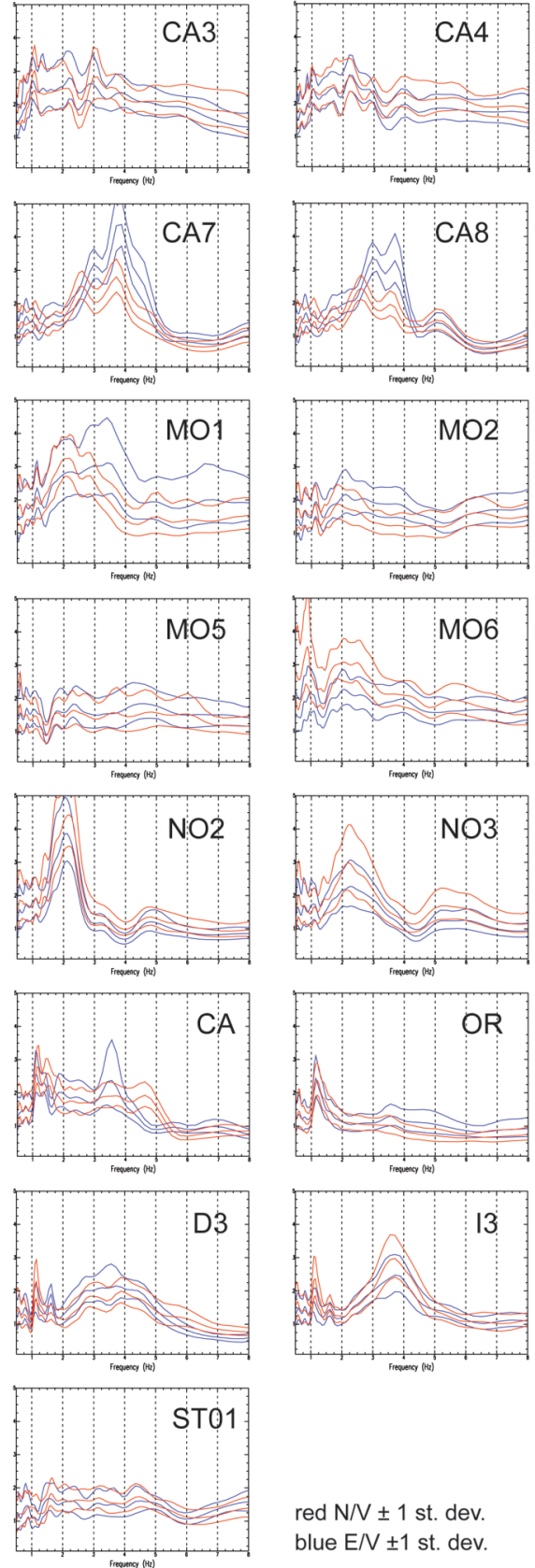
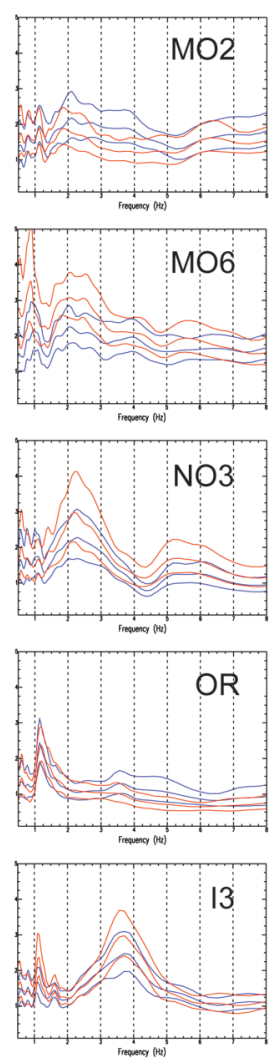

red $N / N \pm 1$ st. dev blue $\mathrm{E} N \pm 1$ st. dev.

Fig. 14. Horizontal to vertical $(H / V)$ spectral ratios of seismic noise measurements from the Cavola area, with separate values shown for the north and east components. The locations of the measurement sites are shown in fig. 4. For all selected windows, which were of length $60 \mathrm{~s}$, the $H / V$ spectral ratios were computed using the Konno and Ohmachi (1998) smoothing algorithm, with smoothing constant 40. The means and standard deviations of the spectral ratios have been determined from at least 30 such windows at each site. 
surrounding the Cavola array. Stations A3, D3, I3, CA6, CA7, CA8, M3, CA5, and P3 are strictly from the array area (with $\mathrm{P} 3$ re-occupying site CA5), stations $\mathrm{CH}, \mathrm{SC}, \mathrm{CA}$ and $\mathrm{OR}$ are from buildings in the Cavola village, stations CA1CA4, DH1, MO1-MO7, NO1-NO3, STO1, CA9, and ORTO are from the area surrounding the array (fig. 4). Among them, some were collected on basement-like rock, with CA5, P3 and CA9 belonging to the Marne di Monte Piano Unit, $\mathrm{CH}$ to the Ranzano Sandstone Unit and ST01 to the Monte Venere Unit.

Note that stations A3, D3, I3, M3, P3, CH, $\mathrm{SC}, \mathrm{CA}, \mathrm{OR}$ and ORTO, and CA9 were recording throughout the experiment, while all the others are measurements lasting less than one hour and acquired either before the experiment (during the reconnaissance trip) or after the experiment.

For the array area, the $H / V$ resonance frequency moves from $2.8 \mathrm{~Hz}$ at site $\mathrm{A} 3$ to around $4.5 \mathrm{~Hz}$ at site CA6 confirming the shift in resonance frequency peak found during the reconnaissance trip (fig. 5) as well as the correlation to surface elevation, with the measurements at the highest elevations having the lowest peak frequencies. In particular I3 (close to borehole2), M3, CA6, CA7, and CA8 stations, located in the lower part of the array on a nearly flat topography, show peaks of 3.5-4 Hz. Regarding the shape of the $H / V$ ratio, this latter group shows one clear peak while a slightly broadened peak is shown by station D3 on the steeply sloping area. Station A3 shows again one clear peak. Stations P3 and CA5 do not show amplification. Landslide thickness can be estimated, under the hypothesis of $1 \mathrm{D}$ behaviour and using a velocity range of 350 to 400 $\mathrm{m} / \mathrm{s}$, as 31-36 $\mathrm{m}$ for site A3, 23-28 $\mathrm{m}$ for site I3, 19-22 $\mathrm{m}$ for site M3, and 19-28 $\mathrm{m}$ for sites CA6-CA8. The 23-28 m depth to the bedrock for I3 is in good agreement with the $25 \mathrm{~m}$ depth to the bedrock of borehole2 and with MASW and refraction results for the same array sector.

The remaining stations just outside the array can be grouped on the basis of their $H / V$ function shape and/or resonance frequency. A first group includes sites NO1, NO2, NO3, MO1, MO6, MO7, DH1 (in proximity of borehole1) and ORTO. They show one clear peak at fre- quencies of 2-2.25 Hz. These sites are just outside the array area on the dormant landslide (fig. 2, right). The similarity of their $H / V$ peak suggests that there is a long N-S line through borehole1 where the depth to basement is almost uniform. Bedrock depth can be estimated as $40-50 \mathrm{~m}$, under the assumption described above. This result agrees with the $44 \mathrm{~m}$ depth to basement found at borehole1 and with the depth to basement indicated by the surface wave analyses along refraction line $X-X^{\prime}$. Frequencies around $2 \mathrm{~Hz}$ could be also found at the landslides sites CA2, CA3, CA4. However, their $H / V$ is not a narrow peak but more plateau-like. This might be the result of a weak velocity contrast or more complex layering.

The bedrock sites show almost flat $H / V$. Of these, actual basement sites include P3, ST01, $\mathrm{CH}, \mathrm{CA} 5 \mathrm{CA} 9$, and MO3. Sites MO2, MO5 and MO4 are on the dormant landslide but very close to the Ranzano Sandstone Unit outcrops at the western side of the array. The $H / V$ ratios of sites MO2 and MO5 show no amplification up to $8 \mathrm{~Hz}$ indicating a very shallow cover of the landslide, which is confirmed by a pre-existing very shallow borehole close to MO2 site where the depth to bedrock is between 3-5 m. Site MO4 has unexpectedly large spectral ratio and a peak frequency of $3.75 \mathrm{~Hz}$, possibly due to its location on filled land where there has been recent building activity. ST01 is the only measurements on the marly-calcareous flysch of the Monte Venere Unit, outcropping east of the array area, and its $H / V$ is flat.

Finally, there is a last group of sites including SC, CA and OR, showing responses with intermediate characteristics that are not easily interpretable. Their features could be related to cultural noise and/or to more complex layering.

As a final remark, the spectral ratio at sites CA6, CA7 and CA8 (fig. 5) during our reconnaissance field trip in early spring showed higher E-W component $H / V$ spectral ratio compared to the N-S component $H / V$ spectral ratio. This preliminary observation was not confirmed by the selection of the array data we analyzed or by the noise measurements performed subsequently in the area. Another intriguing feature of the $H / V$ spectral ratios is the presence of a common and narrow 1-1.2 Hz peak at two thirds of the sites, 
including basement sites. The amplitude of the 1-1.2 Hz peak varies with time. The measurements CA5, CA6, CA7 and CA8 do not have clear peaks at 1-1.2 Hz. This particular group of measurements, without clear peaks at $1-1.2 \mathrm{~Hz}$, were in the same area as the array sites A3, D3, I3, M3 and P3, with clear peaks at 1-1.2 Hz. The spectral ratio variations in time could be related to variations in the locations of noise sources, but also possibly to properties of the landslide body. In order to resolve this ambiguity we are processing the entire noise sequence recorded by the array (spanning from summer to autumn). Preliminary results indicate that intermittent human activity strongly influences both the level and the character of the noise. In the area there are ceramics factories which likely cause this peak at $1-1.2 \mathrm{~Hz}$.

Figure 12 (bottom) shows a preliminary 2D model of the landslide, reconstructed along a NE-SW profile from site P3 to site MO2, that summarizes all the data collected.

\section{Conclusions}

We have explained the motivation for the deployment of the seismic array at Cavola. The Northern Apennines are prone to landslides due to the geomechanical characteristics of the basement geology. The rocks have been subjected to much tectonism, resulting in weakening through fracturing and faulting. Many villages throughout the region are sited in potentially unstable situations. There is continuous seismicity, with high intensities of ground shaking likely to occur with sufficient regularity to be of considerable concern. There has been destructive movement of the Cavola landslide associated with meteorological activity in the last century, with the potential for even more destructive movement should such activity coincide with a large earthquake.

Provincia di Modena and Provincia di Reggio Emilia were, therefore, interested in studying the seismic response of such a landslide, with detrital cover over cracked basement. This has not been investigated before, and they proposed the Cavola village and its landslide as our study area.
The heterogeneity of a landslide requires dense station spacing to quantify short scale variation in response. We deployed an array of 95 3-component GURALP CMG-6TD stations, designed to be dense enough to follow the propagation of the seismic waves from station to station along the array, to quantify variation of site response over short distance and ultimately to compare unambiguously modelling and observations in the frequency band of amplification $(2.5-4.5 \mathrm{~Hz})$.

This paper deals with characterising the geometry and the velocities of the Cavola landslide and its basement, and with details of the deployment of such a peculiar array. The configuration of the seismic array, with $10 \mathrm{~m}$ spacing in the NE-SW direction and $8 \mathrm{~m}$ in NW-SE direction, has provided us with excellent recordings with a very high degree of continuity between neighbouring stations. In addition, the separate microearthquake network deployed at regional distance throughout the experiment has provided us with an accurate list of earthquakes recorded.

We reconstruct the geometry and the velocities of the landslide and of the basement combining the use of geological, seismic and geophysical surveys.

At the pre-existing borehole1 the bedrock was below $44 \mathrm{~m}$ of landslide deposit. We drilled a new borehole within the array, borehole2, where the depth to the bedrock was $25 \mathrm{~m}$. Here down-hole logging of $P$-wave and $S$-wave travel times was performed. The $P$-wave velocities that were obtained are $520 \mathrm{~m} / \mathrm{s}$ in the top $3 \mathrm{~m}$ above the water table, $1630 \mathrm{~m} / \mathrm{s}$ in the body of the landslide, and $2850 \mathrm{~m} / \mathrm{s}$ in the basement. For $S$-waves the velocities are $230 \mathrm{~m} / \mathrm{s}$ and 625 $\mathrm{m} / \mathrm{s}$ above the water table and in the basement respectively, while in the landslide below the water table the $S$-wave velocity increased approximately linearly with depth from about 300 $\mathrm{m} / \mathrm{s}$ at the top to a value very close to that in the basement at the bottom $(625 \mathrm{~m} / \mathrm{s})$.

Two seismic refraction lines were analysed, through conventional $P$-wave refraction profiling as well as a combination of surface wave analyses, giving depths to basement and $P$ and $S$ waves velocity in agreement with the depths at the two boreholes. Seismic noise measure- 
ments have provided further confirmation of the depth to basement, and extended the area over which we have information about the landslide thickness. Within the array the resonance frequencies vary from $2.7 \mathrm{~Hz}$ to $4.5 \mathrm{~Hz}$ and are clearly related to the thickness of the landslide body and to the topography. At several stations we found intriguing variations in time of the amplification function peaks which we are investigating and will be reported in detail in a later paper. A preliminary $2 \mathrm{D}$ model of the landslide is presented, which summarize all the data collected through the multidisciplinary approach used here.

\section{Acknowledgements}

The project was co-funded by i) Area Ambiente e Sviluppo Sostenibile of Provincia di Modena; ii) Area Pianificazione e Tutela del Territorio of Provincia di Reggio Emilia; iii) Servizio Tecnico of Comune di Toano; iv) Servizio Geologico, Sismico e dei Suoli of Regione Emilia Romagna; and v) Istituto Na-zionale di Geofisica e Vulcanologia, Centro Na-zionale Terremoti (INGV).

We thank the Editor Massimo Cocco, Luigi Improta and an anonymous reviewer for their constructive reviews.

We also thank the down-hole staff from Università degli Studi di Firenze Dipartimento di Ingegneria Civile, Sezione di Geotecnica, for the down-hole logging, Maurizio Pignone from IN$\mathrm{GV}$ for providing the CSI 1.1 catalogue in a convenient ArcGIS format, Giovanni Bertolini from Regione Emilia Romagna for providing an unpublished photograph of the Cavola landslide, the owner of the Cavola field Sig. Valentino Monticelli for his kind hospitality, and Laura Bissoli, Luca Lenti, Giuseppe Coco, Justin Grounds and Mark Haines for helping in the field work. As well, we particularly thank NERC SEIS-UK for allowing us to use their superb equipment and for the excellent technical support provided.

Luciano Giovani passed away recently. His expertise and experience was very important not only in the field work but also in the organization and management of the experiment.

\section{REFERENCES}

Almagià, R. (1907): Studi Geografici sulle frane in Italia, Mem. Soc. Geogr. It., 13 (1), 1-342.

Bettelli, G. and M.T. De NARdo (2001): Geological outlines of the Emilia Apennines (Italy) and introduction to the rock units cropping out of the areas of landslide reactivated in the 1994-1999 period, Quad. Geol. Appl., 8, 1-26.

BERNABINI, M. (1965): Alcune considerazioni sui rilievi sismici a piccole profondità, Boll. Geofis. Teor. Appl., II (26), 106-18.

Bertolini, G. and M. Pellegrini (2001): The landslide of the Emilia Apennines (Northern Italy), with reference to those which resumed activity in the 1994-1999 period and required Civil Protection interventions, Quad. Geol. Appl., 8, 27-74.

Bertolini, G. and M. PizZiolo (2007): The reactivation of ancient landslides in the Emilia-Romagna Region (Italy): risk-reduction strategies (available on line at: http://www.regione.emiliaromagna.it/wcm/geologia_en/ News/2007_landslides_reactiv.htm).

Brunamonte, F. (1999): Catalogo delle Frane Storiche Provincia di Reggio Emilia.

CAPON, J. (1969): High-resolution frequency-wavenumber spectrum analysis, Proc. IEEE, 57 (8), 1408-1418.

Castello, B., G. Selvaggi, C. Chiarabba and A. Amato (2005): CSI Catalogo della Sismicità Italiana 19812002, versione 1.0. (INGV-CNT, Roma), (available on line at: http://www.ingv.it.CSI/).

Cerrina Feroni, A., L. Martelli, P. Martinelli and G. OtTRIA, WITH THE CONTIBUTIONS OF R. CATANZARITI (2002): Carta Geologico-Strutturale dell'Appennino EmilianoRomagnolo alla scala 1:250000 (Regione Emilia-Romagna, Servizio Geologico, Sismico e dei Suoli, CNR, Istituto di Geoscienze e Georisorse, Pisa, SELCA, Firenze).

Chiarabba, C., L. Jovane and R. Di Stefano (2005): A new view of Italian seismicity using 20 years of instrumental recordings, Tectonophysics, 395, 251-268.

CNR-RER (1993): Atlante dei Centri Abitati Instabili dell'Emilia-Romagna, a cura di A. ANNOVI and G. SIMONI (CNR, Gruppo Nazionale per la Difesa dalle Catastrofi Idrogeologiche, Regione Emilia-Romagna, Programma speciale SCAI, Presidenza del Consiglio dei Ministri, Dipartimento della Protezione Civile, Roma).

Corsini, A., P. Farina, G. Antonello, M. Barbieri, M., N. Casagli, F. Coren, L. Guerri, F. Ronchetti, P. SterZAI and D. TARCHI (2006): Space-borne and groundbased SAR interferometry as tools for landslide hazard management in civil protection, Int. J. Remote Sensing, 27 (12), 2351-2369.

Frepoli, A. and A. Amato (1997): Contemporaneous extension and compression in the Northern Apennines from earthquake fault plane solutions, Geophys. J. Int., 129, 368-388.

GRUPPO DI LAVORO CPTI (2004): Catalogo Parametrico dei Terremoti Italiani, versione 2004 (CPTI04), (INGV, Bologna), (available on line at: http://emidius.mi.ingv.it/ $\mathrm{CPTI} /$ )

KonNO, K., and T. OHMACHI (1998): Ground motion characteristics estimated from spectral ratio between horizontal and vertical components of microtremor, 1998, Bull. Seismol. Soc. Am., 88 (1), 228-241. 
LAHR, J.C. (1999): HYPOELLIPSE: a computer program for determining local earthquake hypocentral parameters, magnitude, and first-motion pattern (Y2K Compliant Version), U.S. Geol. Surv. Open-File Rep. 99-23.

Lollino, G., O. Turitto, P. Allasia, C. Audisio, M. BalDo, D. Giordan, F. Godone, E. Guglielmi, G. NigrelLI and C. RIVAROSSA (2005): Rapporto Semestrale per il Monitoraggio Morfologico e Sedimentologico Finalizzato a una Corretta Attività e Manutenzione dei Corsi d'Acqua (AIPO and CNR-IRPI).

LouIE, N.J. (2001): Faster, better shear-wave velocity to $100 \mathrm{~m}$ depth from refraction microtremor arrays, Bull. Seismol. Soc. Am., 91, 347-364.

Mancin, N., L. Martelli and C. BARBIERI (2006): Foraminiferal biostratigraphic and paleobathymetric constraints in geohistory analysis: the example of the EpiLigurian succession of the Secchia Valley (Northern Apennines, Midlle Eocene-Late Miocene), Boll. Soc. Geol. It., 125, 163-186.

Martelli, L., U. Cibin, A. Di Giulio and R. Catanzariti (1998): Litostratigrafia della Formazione di Ranzano (Priaboniano-Rupeliano, Appennino Settentrionale e Bacino Terziario Piemontese), Boll. Soc. Geol. It., 117, $151-185$.

PAPANI, G. (Editor) (2002): Carta Geologica d'Italia alla scala 1:50.000, Foglio 218 Castelnovo ne' Monti (Ser- vizio Geologico d'Italia, Regione Emilia-Romagna, Servizio Geologico, Sismico e dei Suoli, SELCA, Firenze).

Plesi, G. (Editor) (2002): Carta Geologica d'Italia alla scala 1:50.000, Foglio 235 Pievepelago (Servizio Geologico d'Italia, Regione Emilia-Romagna, Servizio Geologico, Sismico e dei Suoli, SELCA, Firenze).

Pondrelli, S., A. Morelli, G. Ekström, S. Mazza, E. BosCHI and A.M. DZIEWONSKI (2002): European-Mediterranean regional centroid-moment tensors: 1997-2000, Phys. Earth Planet. Int., 130, 71-101.

SeSAme Project (2001-2004): Site EffectS using AMbient Excitations (available on line: http://sesame-fp5.obs.ujfgrenoble.fr).

SESTINI, G. (Editor) (1970): Development of the Northern Apennines geosyncline, Sedim. Geol., 4, 341-444.

WATHELET, M. (2005): Array recordings of ambient vibrations: surface-waves inversion, Ph.D. Thesis (University of Liege, Belgium), pp. 177.

Wathelet, M., D. Jongmans, M. Ohrnberger and S. BonNEFOY-CLAUDET (2008): Array performances for ambient vibrations on a shallow structure and consequences over Vs inversion, J. Seismol., 12, 1-19.

(received July 1, 2007;

accepted November 26, 2007) 